\title{
Dosing of Education for Patients Newly Diagnosed with Multiple Sclerosis
}

\author{
Laura K. Miller \\ University of St. Augustine for Health Sciences \\ DOI: https://doi.org/10.46409/sr.YHHO4369
}

Follow this and additional works at: https://soar.usa.edu/dissertations

Part of the Diagnosis Commons, and the Nervous System Diseases Commons

\section{Recommended Citation \\ Miller, L. K. (2017). Dosing of Education for Patients Newly Diagnosed with Multiple Sclerosis. [Doctoral project, University of St Augustine for Health Sciences]. SOAR @ USA: Student Dissertations Collection. https://doi.org/10.46409/sr.YHHO4369}


Dosing of Education for Patients Newly Diagnosed with Multiple Sclerosis

by

Laura K. Miller

has been approved

February 2017

APPROVED:

ERIC OESTMANN, PhD Faculty Mentor and Chair

MARK R. WIEGAND, PT, Ph.D., Committee Member

ACCEPTED AND SIGNED:

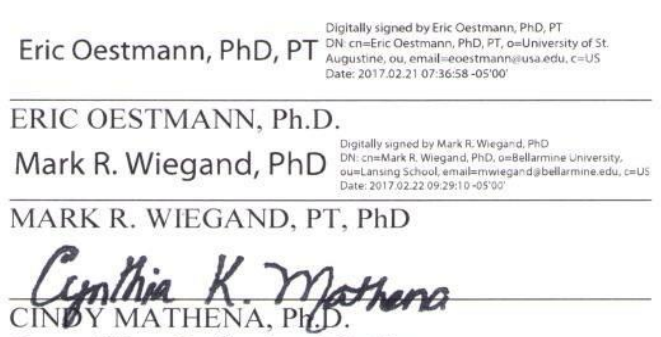

Dean of Post Professional Studies 


\begin{abstract}
The value of patient education has been widely documented in various patient populations. The main focus of this study is to evaluate the timing of patient education in correlation with the time since diagnosis. The goal of this study is to make recommendations for the optimal time in which patient education should be delivered following a diagnosis of Multiple Sclerosis (MS). This study evaluates self-advocacy using the Patient Self-Advocacy Scale (PSAS) which was completed pre and post educational programs. This data, combined with demographic data was analyzed for any relationships. Although no statistically significant findings were established, many important trends in data were noted which support the need for patient education.
\end{abstract}




\section{Dedication}

To Mary Colleen Battcher, who shared my love of education and inspired my passion for patient education. 


\section{Acknowledgements}

For the past several years I have received constant support and encouragement from a great number of individuals. Dr. Mark Wiegand has been a professor, mentor, colleague and friend. His constant support and guidance has made this journey possible and I am immensely grateful for his efforts on this project. I would like to thank Dr. Eric Oestmann for his feedback and excellent support as an advisor. In addition, Dr. Dan Lofald has provided me with invaluable advice and guidance for statistical analysis.

The faculty at Bellarmine University has provided great support and encouragement throughout my entire academic work and I am proud to be part of that family. Autumn Clegg has been an invaluable friend and peer who has supported me along the way and reminded me to stay focused. Finally, thanks to Tony Brosky and Elaine Lonnemann for the push to pursue this degree. 
Table of Contents

Acknowledgements

vi

Table of Contents

vii

List of Tables

ix

List of Figures $\quad$ X

Chapter 1: INTRODUCTION 1

Introduction \& Background 1

Statement of the Problem 3

Purpose of the Study 3

Research Questions/Hypotheses 3

Significance of the Study $\quad 5$

$\begin{array}{ll}\text { Assumptions } & 6\end{array}$

Nature/Organization of the Study 6

Chapter 2: LITERATURE REVIEW

$\begin{array}{lr}\text { Introduction } & 8\end{array}$

$\begin{array}{ll}\text { Patient Education } & 11\end{array}$

Self-Efficacy and Advocacy 22

$\begin{array}{ll}\text { Cognitive Load Theory } & 28\end{array}$

Coping, Cognitive and Psychological Impairments in MS 30

Guiding Contemporary Research/Summary 36

Chapter 3: METHODOLOGY

$\begin{array}{ll}\text { Introduction } & 40\end{array}$

Statement of the Problem 41

Research Questions/Hypotheses $\quad 42$ 
Population \& Sample $\quad 43$

$\begin{array}{ll}\text { Instrumentation } & 45\end{array}$

Data Collection Procedures $\quad 46$

$\begin{array}{ll}\text { Procedure } & 46\end{array}$

$\begin{array}{ll}\text { Data Analysis } & 47\end{array}$

$\begin{array}{ll}\text { Dependent Variables } & 47\end{array}$

$\begin{array}{ll}\text { Independent Variables } & 48\end{array}$

$\begin{array}{ll}\text { Confounding Variables } & 49\end{array}$

Ethical Issues $\quad 49$

Limitations/Delimitations $\quad 49$

Chapter 4: RESULTS

$\begin{array}{ll}\text { Introduction } & 51\end{array}$

Study Participants’ Demographics $\quad 51$

Central Hypothesis $1 \quad 56$

$\begin{array}{ll}\text { Central Hypothesis } 2 & 63\end{array}$

Secondary Analysis $\quad 64$

Chapter 5: CONCLUSIONS AND RECOMMENDATIONS

$\begin{array}{ll}\text { Introduction } & 65\end{array}$

$\begin{array}{ll}\text { Key Findings } & 69\end{array}$

$\begin{array}{ll}\text { Limitations of the Study } & 71\end{array}$

$\begin{array}{ll}\text { Recommendations for Future Research } & 74\end{array}$

$\begin{array}{ll}\text { Researcher Observations } & 78\end{array}$

$\begin{array}{lr}\text { REFERENCES } & 80\end{array}$ 


\section{LIST OF TABLES}

1. Table 4-1. Descriptive Statistics for Age of Study Participants

2. Table 4-2. Descriptive Statistics for Marital Status of Study Participants

3. Table 4-3. Descriptive Statistics for Number of Children of Study Participants

4. Table 4-4. Descriptive Statistics for Race of Study Participants

5. Table 4-5. Descriptive Statistics for Family Members with MS

6. Table 4-6. Descriptive Statistics for Level of Education of Study Participants

7. Table 4-7. Descriptive Statistics for Employment Status of Study Participants

8. Table 4-8. Descriptive Statistics for Household Income of Study Participants

9. Table 4-9. Descriptive Statistics for Pre and Post PSAS Scores

10. Table 4-10. Descriptive Statistics Interval from Discharge of Study Participants

11. Table 4-11. Spearman rho Correlation between Interval from Diagnosis and Pre/Post Change Score

12. Table 4-12. Pearson Correlation between Pre Score Total and Age

13. Table 4-13. Spearman rho Correlation between Pre Score Total and Education 


\section{LIST OF FIGURES}

1. Figure 4-1. Bar Chart Pre/Post PSAS Scores

2. Figure 4-2. Scatter Plot of Relationship between Interval and Pre/Post Change Scores 



\section{CHAPTER 1: INTRODUCTION}

\section{Introduction and Background}

Recent research has shown the benefits of a multidisciplinary approach to the treatment of Multiple Sclerosis (MS). (Burks, 2000; Halper, 2010; Namey, 2010). This includes many new treatment options including disease-modifying medications. However, many patients live in areas with limited access to care, are not provided with appropriate information to effectively self-advocate in disease management. There is no current standard regarding the optimal amount and timing of disease information provided to patients after receiving a diagnosis of Multiple Sclerosis.

Treatment of MS includes medication management and monitoring of disease progression by a physician or nurse practitioner. There is also a significant amount of research supporting the benefits of a multidisciplinary approach to MS management, including nursing, rehabilitation experts, social workers, nutritionists and mental health practitioners, and others. Due to the wide range of clinicians involved in care, there is potential for education to be completed in various settings and depending on the healthcare system, there may be little to no communication between providers. The goal of this research is to standardize the timing of education provided to patients newly diagnosed with MS to maximize their ability to act as their own advocates for healthcare needs.

One of the challenges of caring for people with MS in less populated areas is the lack of access to healthcare specialists. In some instances, a general neurologist or physical therapist may provide patient care instead of providers with specialized training in the management of patients with MS. There is a growing trend of larger healthcare 
systems to guide patients towards specialists to optimize care. In these larger systems, there are often resources available to support medical care through support groups, exercise programs, educational programs and access to a wider variety of medical professionals. One strategy for supporting the medical treatment of MS is to offer educational programs provided by a variety of clinical specialists.

Many larger healthcare systems have access to expert clinicians of varying specialties of care to provide patient education. A common model is for routine educational programs to be offered for newly diagnosed patients with MS. Depending on when patients are diagnosed and/or their availability to attend, there is variable timing for when these classes might take place. In one healthcare system, a four-hour educational program titled "MS 101" is offered quarterly. The neurologist encourages patients to attend the next available course following a definitive diagnosis of MS. However, depending on the timing and patient availability, several months or years may pass before the patient might attend this program. In other cases, patients may attend a session the first week they are diagnosed, when the news is still very novel.

A current model for this educational program includes information from social workers, nurses and mental health professionals. The medical team is introduced, resources available to patients are presented and discussions about disease progression, including the disability process and mobility options are addressed. Depending on the patients' attitude, this information may be overwhelming or depressing, or patients may feel that some of this information may negatively impact their future outlook. Other individuals may receive this information and process it all, and may find most of it relevant to their individual needs. 


\section{Statement of the Problem}

The problems related to education in patients with Multiple Sclerosis are multifactorial. The first challenge is the potential for patients to be overwhelmed with new information shortly after being diagnosed with this progressive neurologic condition. The second problem is that if patients are not educated in a timely manner, they may have low self-efficacy, autonomy and ability to advocate for personal needs. This may lead to limited ability to participate in treatment decisions based on those needs. In modern day healthcare systems, there is increased need for patients to be active participants with health care providers in decision making related to the care of their condition. Poor timing of education can potentially impact a patient's self-efficacy as well. If education is not quickly received patients may be ineffective in self advocacy. Conversely, providing too much education too quickly may overwhelm patients with information.

\section{Purpose of the Study}

The purpose of this study is to determine the appropriate amount and timing of education to patients that are newly diagnosed with Multiple Sclerosis to maximize selfefficacy. The goal is to determine patient cognitive load after receiving a diagnosis of a progressive neurological condition and tailor educational programs to best meet patient needs. An additional purpose is to identify the patient's perceived ability to act as their own advocate following diagnoses of a progressive neurologic condition.

\section{Research Questions/Hypotheses}

Research Question 1: How does the timing of patient education affect self-advocacy in patients with MS? 
Research Question 2: How does the amount of information provided to patients with MS impact their self-advocacy?

Research Question 3: What demographic information correlates with self-advocacy?

Research Question 4:What are the optimal time frames in which diagnosis education should occur?

Research Question 5: How much information can patients with a progressive neurologic condition absorb in the acute phase of diagnosis?

\section{Hypotheses}

H1 (Null): There is no relationship between the timing of education and patient selfadvocacy.

H1 (Alternate): There is a relationship between the timing of education and patient selfadvocacy.

H2 (Null): The amount of education has no impact on self-advocacy.

H2 (Alternate): The amount of education provided negatively impacts self-advocacy. H3 (Null): There is no correlation between demographics and patient reported selfadvocacy.

H 3 (Alternate): There is a correlation between demographics and patient reported selfadvocacy.

H4 (Null): There is no correlation between timing of patient education and selfadvocacy.

$\mathrm{H} 4$ (Alternate): There is a correlation between the timing of patient education delivery and self-advocacy. 
H5 (Null): There is no relationship between the amount of information provided to patients and reported self-advocacy.

H5 (Alternate): There is a relationship between the amount of information provided to patients and reported self-advocacy.

My hypothesis is when provided with four hours of education close to the time of diagnosis (less than 2 months), patient retention and self-efficacy will be poor. I also believe demographic data contributes to the self-efficacy of patients with Multiple Sclerosis.

\section{Significance of the Study}

The goal of this study is to determine how much education should be provided to newly diagnosed patients with Multiple Sclerosis and when that information should be provided. Clinical observation and the literature have shown that there is a wide variety of educational models for individuals with MS. Patients are educated at varying points after receiving the diagnosis and this may impact the ability to effectively self-advocate. Self-advocacy has been well studied in cancer, mental illness and AIDS patients and has been shown to positively affect the quality of care patients receive. (Brashers et. al, 1999; Jonikas et. al, 2013; National Mental Health Clearinghouse). This study should offer guidelines on the optimal amount and timing to provide the information to patients about MS and treatment options. By improving these factors, patients should more effectively advocate for themselves, obtain better care and outcomes with improved quality of life. There is potential to standardize this information throughout MS centers to better educate and optimally treat these patients. 
Research studies have shown that patient education programs provided in acute care settings lead to decreased readmission rates and decreased follow-up visits to emergency rooms, suggesting a decrease in overall healthcare costs. (Jack et. al, 2009).

\section{Assumptions \& Limitations}

In this research, it is assumed that patients with Multiple Sclerosis who choose to attend educational program after a diagnosis are motivated to better advocate and to participate in decision making related to treatment. It is assumed that participants in the MS 101 courses will provide accurate demographic information and healthcare professionals that lead the course are sufficiently trained and considered to be experts in the area of Multiple Sclerosis.

There are limitations to this study, including patient willingness to participate in MS 101. The dates, times, and locations of the course, as well as personal motivation may affect patient participation. Three MS 101 courses will be used for analysis and will take place on different days and different times of day. Additional limitations may be accurate reporting from participants completing pre and posttest information and the

analysis of education programs is from three courses provided only at Norton Healthcare in Louisville, KY.

\section{Nature/Organization of the Study}

Patients who choose to participate in the MS 101 courses offered in the second half of 2016 will be asked to provide demographic data and the date of MS diagnosis. They will complete a pre-course Patient Self-Advocacy Scale (PSAS). The study will categorize patients based on elapsed time since diagnosis and compare self-efficacy scores before and after the educational program, MS 101. An ANOVA comparison will 
compare patients in various timeframes since diagnosis and scores on their self-efficacy outcomes. 


\section{CHAPTER 2 - LITERATURE REVIEW}

\section{Introduction}

Multiple Sclerosis (MS) is a chronic and progressive disease affecting the central nervous system. As an immune-mediated disorder in which the immune system destroys myelin, the protective sheath around nerves, MS results in slowed conduction of nerve signals and manifests itself in a wide variety of clinical presentations. Currently, there are about 400,000 individuals living with MS in the United States. Typically, the onset of symptoms occurs between ages 20-40, affects women more than men, and has no significant impact on life-span. MS symptoms are highly variable from person to person; common signs and symptoms may include optic neuritis, weakness, paresthesias, pain, fatigue, cognitive impairments or balance deficits. Optic neuritis is an inflammatory process of the optic nerve that presents as unilateral eye pain or vision problems, usually occurring early on in the disease process. Paresthesias are a common initial symptom of MS, presenting as numbness, tingling or atypical pain throughout the body. The National MS Society estimates that at least half of all patients with MS will develop cognitive impairments at some point. There are several possible presentations including impairments in memory, attention, information processing, decision-making and word finding. Memory impairments typically affect short-term memory or the ability to recall things for brief periods of time, while long term memory is generally unaffected. Impairments in information processing typically affect the ability to interpret information gathered through verbal, visual or sensory delivery. Currently, there is no specific diagnostic test for MS, but a diagnosis is generally made by a neurologist' $\mathrm{s}$ interpretation of magnetic-resonance imaging (MRI) results, lumbar puncture to test for presence of 
oligoclonal bands in the cerebrospinal fluid, and possibly nerve-conduction velocity testing.

Currently, there is also no cure for MS. Instead the disease is managed through disease-modifying therapies (DMTs), a class of drugs new to the market in the past two decades, which are designed to slow disease progression. DMTs and serial imaging are managed in most cases by a neurologist, but there is significant need for a multidisciplinary approach to care for patients with MS. Ideally, the treatment team should include the neurologist and neurologic nurse practitioner, a registered nurse $(\mathrm{RN})$ that specializes in the management of MS, mental health providers, social workers and a rehabilitation team including physical, occupational and speech therapists. Halper (2010) defined the importance of an MS nurse to facilitate patient education including information about the diagnosis, treatments, and access to resources. Gallien et. al. (2014) has described the value of multidisciplinary care models to treat MS given the complexity of the disease. This paper discussed the role of neuropsychology including cognitive and psychological impairments that should be treated in collaboration with psychiatry, psychology, and speech therapy to comprehensively address the impairments from both medical and non-medical approaches. A similar model for pain management was suggested including rehabilitation professionals, nursing, pharmacotherapy, and medical management.

There are four major classifications of MS according to the National MS Society: relapsing-remitting, primary progressive, secondary progressive and progressiverelapsing. Relapsing-remitting is the most common form of MS affecting about $85 \%$ of patients and is characterized by periods of active inflammation and demyelination in the 
CNS followed by periods of remission or stability of the disease. Primary progressive MS is defined as worsening neurologic function from the time of diagnosis with or without relapses and remissions. This form of MS affects about $15 \%$ of patients. (National MS Society). Secondary progressive MS (SPMS) typically begins as a relapsing-remitting course and transitions to SPMS when there is progressive worsening or neurologic decline over time. Patients with SPMS may experience worsening of neurologic function even during times where there is no active inflammatory process or demyelination occurring. Progressive-relapsing MS is characterized by a steady decline in function from the time of diagnosis with occasional periods of relapse and is considered to be a form of primary progressive MS. (Halper, 2010; National MS Society).

MS is typically managed with disease-modifying therapies (DMTs) to decrease the frequency and intensity of exacerbations or active inflammatory processes that result in demyelination of nerves. Once a neurologist has confirmed a diagnosis of MS, they select the DMTs that are most appropriate for that patient based on potential side effects and risks associated with each drug. Routine MRI studies and clinical examinations by a neurologist are utilized to assess for disease progression including MRI changes indicating active demyelination or clinical worsening of symptoms or patient presentation. In the event of MRI changes or clinical progression, a neurologist can determine if the patient is having a suboptimal response to their DMT and whether the medication should be altered. Adjunct medical therapies may be indicated for symptom management including spasticity control, bowel and bladder dysfunction, fatigue, sleep 
disorders or pain. The neurologist also facilitates referral to other healthcare providers for additional support in management of MS.

The Multiple Sclerosis Association, Multiple Sclerosis Society and local chapters or centers are a primary source of information and resources for people with MS. These organizations offer information on a variety of topics related to MS, and often host live seminars or educational programs related to the disease. Kieseier (2015) discussed the dynamic nature of MS and the evolving treatments available as disease-modifiers or adjunctive therapies, stressing the importance of education of patients and healthcare providers.

\section{Patient Education}

The need for lifelong management of progressive neurologic diseases such as MS have been well Described. (Feicke, 2014, Gallien et. al., 2014; Halper, 2010; Kieseier, 2015; Matti et.al. 2010.) Treatment approaches to MS have changed significantly over the past several years. (Kiesier, 2015) The past two decades have allowed for development of thirteen Food and Drug Administration (FDA) approved DMTs as well as improved magneticresonance imaging (MRI) techniques to monitor disease progression. Additionally, public understanding of the nature and management of progressive neurologic diseases has increased recently.

Gallien et. al. (2014) described the importance of treatment of individuals with MS being multimodal and interdisciplinary. This study delineates the importance of a collaborative team of neurologists, physical therapists, occupational therapists, speech language pathologists and other healthcare providers in the management and treatment of the person with MS. However, it may be important to educate patients on the expertise of 
each provider in order to clearly express their needs to the appropriate provider. There are many studies that highlight the effectiveness of educational programs in management and compliance of treatment in progressive conditions. (Fraser, 2009; Holman 2004). Bishop and Frain $(2007,2011)$ have identified five components of MS-specific selfmanagement abilities. These dimensions include treatment adherence and barriers, understanding and actively learning about MS, managing one's health, being an active participant in decision making, and managing the impact of MS on life. These components are based on the foundational education that was provided to individuals at or near the time of diagnosis. Patients must first receive education on MS and various treatment options available to become active participants in the decision making process. Furthermore, all of these components are addressed in the MS 101 program to assess the correlation between MS education and self-efficacy.

Kopke et. al. (2009) studied the relationship between patient autonomy and management of relapses in MS. In this study, 150 people with relapsing-remitting MS were provided education about their disease in a structured group format after being provided with written educational materials prior to attending the course. The educational information provided data on the option of oral corticosteroid or 3-day high dose intravenous steroids in the event of an acute relapse. The control group received educational materials regarding only disease relapse and the use of corticosteroids therapies. Participants were followed for two years with periodic phone calls to inquire about relapses. The authors concluded that the structured educational program had a significant impact on patient decision-making ability and autonomy when it came to the treatment of acute relapses of their MS. The structured education focused on recognition 
of an actual relapse compared to possible pseudo-relapse and when to contact a physician for assistance. Patients that received the structured educational information were less likely to pursue the use of steroids and were more cautious in their use of these drugs. Patients were followed for two years, and there were no significant differences between groups for quality of life or disability statues. In this study, structured educational interventions were associated with improved management of relapses, decreased use of steroids and overall improved autonomy. (Kopke, 2009). The limitations of this study include the lack of blinding of outcome evaluators, which potentially could have biased participant's decisions. Additionally, there were no clinic visits to discuss relapse treatment, physicians were blinded to allocation of each patient, and there was no ability for investigators to assess time between acute relapse and initiation of treatment as a component of autonomy. There are several strengths to this study including well researched outcome measures, recruitment via media to generalize the population and education provided by specially trained nurses or patients with MS to standardize information and make the study transferrable to other populations.

The Center for Advancing Health (2014) has defined patient engagement as the efforts to maximize the benefits of the healthcare services to which they have access. Historically, individuals with MS had limited treatment options and DMTs had side effects and risks. More recently, additional DMTs have been approved and now 13 such treatment options exist. The addition of new DMTs has offered improved efficacy in disease control but has also have increased side effects. Newer drugs have improved ability to decrease the frequency and intensity of demyelinating and inflammatory attacks, but increased drug efficacy means greater risk. This intensifies the need for 
patient education on treatment options and medication risks. (Center for Advancing Health, 2014).

Bjornevik et. al. (2016) investigated the association between educational level and risk of MS in a study comparing 953 patients with confirmed MS to 1717 healthy controls. Norweigians were studied to eliminate geographical variations since this is a known risk factor for MS. Subjects completed surveys about their educational level and covariates of other known risk factors: smoking, exposure to mononucleosis, vitamin D levels or sun exposure and body size. There were significant correlations between risk factors and level of education. Patients with lower levels of education were more likely to spend more time outdoors as an adolescent or be smokers. In this sample, there was a statistically significant association between lower levels of education and risk of MS. The limitations of this study included the presence of non-responders, which indicates possible selection bias and surveys asking for recall of exposure to risk factors as adolescents.

Bishop et. al. (2009) recognized that people who are diagnosed with a neurological condition are likely to seek out information from various sources to educate themselves about their condition and the future. The goal of this research was to identify the most common tools patients utilize to gain information and therefore assist in making recommendations on delivery of information and providing feedback to patients on how best to access information. (Bishop, 2009). As part of a larger project, surveys were mailed to 1000 people with MS with 409 returned for analysis. Respondents identified the places they sought information from the most: internet, books or print, physicians, support groups, local or national MS groups or other. Their findings showed that 
physicians (31.69\%), the internet (27.94\%) and local or national MS agencies (21.64\%) were the most popular sources of information. (Bishop, 2009). A limitation of this study was physician sources of information did not specify physician specialty, suggesting that respondents may utilize primary care physicians or non-specialists, leading to limited or erroneous information. This implies the need for educational delivery in a group setting to be delivered by the most qualified provider providers to ensure evidence-based treatment options. Furthermore, reliance on the internet leads to concerns of quality and accuracy of information. When provided the opportunity, healthcare professionals can steer patients towards optimal internet resources to ensure accuracy. Lastly, the group setting may be beneficial in establishing relationships early with supporting healthcare providers such as therapists, mental health professionals and nurses who may have expertise in the treatment of people with MS. An additional limitation of this work was the likelihood of potential barriers to learning (vision, cognitive impairments) that may limited educational options. (Bishop, 2009).

Somerset et. al. (2001) reported that patients who sought and gained access to information about their MS were more likely to have higher quality of life, improved psychosocial factors and decreased need for feedback or interaction with healthcare professionals. Johnson (2003) proposed that information provided at or near the time of diagnosis allowed patients to formulate opinions that may have a lasting effect on the perception of disease progression. Furthermore, access to critical information on prognosis, treatment, research opportunities, healthy lifestyle and patient rights was associated with improved ability to communicate needs and participate in treatment decision-making. (Bishop, 2009). 
Matti et. al. (2010) investigated the various types and volume of information consumed by newly diagnosed patients with MS in Australia. This research followed up on several studies that had shown people wanted more information than they received from providers and expressed concerns about access to reliable source for information and education. (Forbes et. al, 2007). Forbes et. al. (2007) specifically defined that educational needs were the highest early in the disease process, suggesting this was a critical time for patient education. Matti et. al. (2010) had 23 patients newly diagnosed with MS attend an educational program about the disease and participate in data collection. These 23 patients completed questionnaires over a nine-month period and reported on the volume of information received from physicians, educational programs, MS nurses, and the internet. In this study, the Multiple Sclerosis Society of South Australia and MS specialist nurses provided the most appropriate amounts of information after the diagnosis of MS and confirmed the correlation between of the amount of information received and the professional providing the information. Responders identified the MS Society of South Australia was the most preferred and relevant provider of information. However, patients specifically wanted more information on topics including the symptoms of MS, disease prognosis and disease management. This study reported similar findings to the work of Somerset et. al. (2002) who found that patients in their study also preferred education from nurses with specialized MS training or certifications. Matti also reported that primary care physicians provided the least relevant and smallest volume of information and confirmed the biggest need for patient education was related to symptoms management. (Matti, et. al. 2010). 
Somerset et. al. (2001) surveyed 318 people with MS in Scotland and England who responded to a questionnaire determining patient needs and expectations related to healthcare services. The findings showed that $41 \%$ of patients wanted more feedback or advice related to exercise, $33 \%$ desired additional information on diet and $25 \%$ requested additional information on medications or alternative treatments. Additional data was collected on frequency of healthcare visits within the past year. Few patients (39\%) reported having a consult with a physical therapist in the past year, suggesting a lack of formal education or information provided on exercise. Only $16 \%$ of respondents reported contact with an MS nurse specialist, but about $30 \%$ of patients reported that they wanted that interaction. Additionally, respondents completed the Short-Form 36 (SF-36) which showed poor self-reports health in almost every area except physical function. Furthermore, respondent SF-36 scores indicated poor health status or quality of life when compared to healthy individuals. One of the primary limitations of this study was that some general practitioners requested their patients not participate in the survey-based study. (Somerset, 2001). Somerset also described their study limitations to include the general vagueness of surveys that do not allow for patient commentary. (Somerset, 2001).

Box et. al. (2003) surveyed 2030 people with MS to compare education received with diagnosis year. In 1974 only 14\% of patients diagnosed reported receiving formal education. By 1990, this number had improved to $34 \%$ and in $200072 \%$ of patients were provided with education about the disease. However, $28 \%$ of those diagnosed received no formal education. Additionally, patients reported that the top five areas of education they most desired at the time of diagnosis were: MS symptoms, symptom management, 
medications, disease course and contact with an MS certified nurse. The biggest gap in education found by this study was the management of MS symptoms. (Box, 2003)

Box et. al. (2003) also surveyed patients to rate the level accessing information about MS and approaches to treatment. Patients were asked to rate each survey item on a five point scale ranging from "not difficult at all" to "very difficult." Over $40 \%$ of respondents reported that finding access to clinical trials, information about drugs, emotional changes and new symptoms were difficult or very difficult to access. Patients also responded that their preferred method of educational delivery for this information would be via face-to-face contact with healthcare professionals, MS experts or through leaflets. (Box, 2003).

Heesen et. al. (2007) defined the importance of shared decision making (SDM) in the management of MS. The value of the SDM is the "two-way exchange of information between physician and patient." (Heesen, 2007; pg. 117). In this model, the physician is able to apply evidence-based practice and the patient can offer personal experience and perspectives on disease process and impairments. The study included 100 randomly selected patients with primary-progressive MS from a database of over 1300 patients. Of the 200 people contacted, 169 responded to questions about decisional role preferences, MS risk knowledge and informational interests and preferences. Findings confirmed that $79 \%$ of participants preferred active decision-making roles. The survey also reported information interest areas were treatment of symptoms (specifically gait impairments and physical therapy), use of magnetic resonance imaging (MRI) information related to relapses and complementary medication options. Furthermore, Hessen et. al. correlated information interest to type of MS. MRI use was highest for patients with a relapsing- 
remitting course, while patients with primary-progressive MS were most interested in gait changes and physical therapy. Limitations in the SDM model were some patients did not want active decision-making roles and preferred the physician make critical decisions. Trust between the patient and physician and the ability for both to work together to maximize outcomes were other potential areas of concern. (Heesen et. al., 2007).

Baker (1998) interviewed 13 patients to collect data on MS exacerbation experiences. The interviewees ranged from 32 to 56 years of age, included 10 women and 3 men with MS histories between 1.75 years to 17 years. Baker studied the knowledge gaps, questions, answer strategies and information barriers the patients had during exacerbations. Data was collected in 1-2 hour recorded interviews for exacerbation specific events over the course of the patient's disease. The subjects selected 39 events for further investigation and opportunities to ask professionals about the nature of the symptoms experienced during an attack. Interviewers identified three gaps in patient education: the physical symptoms experienced, emotions experienced and lack of information about medications received during attacks. Not all patients sought out information to answer questions during exacerbations, some reported reading material was helpful, while some reported discussions with healthcare professionals were beneficial. Patients reported confirmation of symptoms and the course of exacerbations as helpful. Barriers to obtaining information were lack of up-to-date resources, generic information that did not address specific situations and symptom denial limited the pursuit of medical attention. Limitations in this study include the small sample size and the interview strategy that allowed for analysis of multiple attack events. 
Bombardier et. al. (2005) defined health promotion as activities capable of improving the general well-bring of patients, and potentially improving physical, social and emotional health. Challenges of health promotion is the lack of provider time with each patient, access to patient resources and funding issues. Also described was the importance of patient responsibility to advocate for needs and participation in decisions related to care. Bombardier et. al. described popular areas of self-advocacy as exercise, stress management, social support, compliance with prescribed therapies and nutrition.

Chiovetti (2006) has referenced many studies that describe the high volume of information that is required following a diagnosis of MS and the overwhelming nature of this process. The author also described the importance of timing information delivery with the management of MS, citing that "providing patients with appropriate and timely information is a key component of MS care." (Chiovetti, 2006 pg. 374). Health literacy is an important aspect of patient education, which is the degree in which patients are able to obtain, process, and understand health information or resources to make decisions about healthcare needs. Effective health literacy requires that patient education be modified to accommodate all levels of education and learning. Otherwise, patients with lower education or literacy levels may not comprehend or misinterpret information, which could lead to unmet healthcare needs and poorer disease management.

Chiovetti (2006) described barriers to learning in the healthcare setting, including cognitive or visual impairments and varying educational level need. The author further discusses the role of nurses with experience in MS as playing key roles in patient education. Furthermore, the author recommended education should occur in friendly environments where patients are not distracted or feel rushed. Chiovetti also 
recommended that education be provided in multiple forms - written and verbal, and should generally occur at appropriate levels for the general population.

Education is a critical component of chronic disease management and should be provided to all patients. There are many possible delivery methods for education including websites and blogs. For adequate education to occur, patients must have access to educational programs and be able to understand and absorb the information being provided. There are also many barriers to education, specific to people with MS including access to resources such as the internet or specialists, access to quality educational programs led by experts in MS care and cognitive or psychological impairments affecting patient's ability to advocate for themselves or manage their disease. Patients may also struggle to identify when to contact healthcare providers and the responsibilities of each provider. There are many factors to be considered by the patient and their family or caregivers at the time of diagnosis, including accepting the implications of a chronic neurological disease. Patients may be overwhelmed with information provided about a disease they have not yet accepted. Additional barriers to education include lack of access to educational programs or the internet, which is a popular method of information-gathering. One of the major values of patient education is that it allows patients to be empowered to be their own advocate and participate in decision-making related to their healthcare needs.

In recent years, the internet has become one of the most popular vehicles of information for patients. Synnot et. al. (2014) reported that many patients utilize the internet as a primary means to gain information about their diagnosis, but that many patients report difficulty understanding information provided on websites. Synnot et. al. 
also reported that some of the most commonly utilized websites for patients to gain information have low readability levels, which likely leaves patients with unanswered questions or inadequate information. (Synnot, et. al. 2015).

\section{Self-Efficacy \& Advocacy}

The National Mental Health Consumer's Self-Help Clearinghouse “Technical Assistance Guide to Self-Advocacy" defines attitudes and abilities required for selfadvocacy development. Two attitudes recommended for patients who wish to advocate for themselves is to believe in themselves and be assertive. The Clearinghouse Guide also discusses the importance of education, further citing the importance of early education instead of reactive educational strategies. Although geared towards mental health, patients with MS may also avoid information until a problem arises, which could delay getting immediate information during an acute relapse. According to the Clearinghouse recommendations, patients should educate themselves early and create their own individualized set of accessible resources. Patients need to approach education from every viewpoint and then tease out information that is specific to personal needs. (National Mental Health Consumers' Self-Help Clearinghouse).

Self-advocacy promotes the importance of patients breaking down a problem and determining the most important part and taking action, according to the National Mental Health Clearinghouse. Section 3 will further discuss how people with MS may have impairments that prevent them from identifying the most important part of a problem or recognizing what parts of the problem that can be impacted. (National Mental Health Consumers' Self-Help Clearinghouse). 
Bandura's work has defined the necessity of self-efficacy in management of disease and in overall psychosocial function. (Bandura, 1977) Furthermore, Bandura defines self-efficacy as an individual's beliefs about their ability to achieve the desired outcome. (Hughes, 2015). This concept has been studied in multiple patient populations, including spinal cord injury epilepsy and diabetes. (Hughes, 2015) Research with various patient populations has indicated that self-efficacy is modifiable and highly associated with functional outcomes and improved quality of life. (Aalto, 1997; Tsaousides, 2009) Studies that have assessed interventions designed to improve selfefficacy have shown improvements in chronic disease management. (Aalto, 1997; Northern, 2001).

Wilski and Tasiemski (2015) identified the relationships between treatment beliefs, illness perception, self-esteem and self-efficacy and self-management of multiple sclerosis. In surveys of 210 people with MS, specific factors related to self-management were identified using multiple tools to identify personal factors that related to selfmanagement of the disease. In this study, the following tools were used: selfmanagement was assessed using the Multiple Sclerosis Self-management Scale Revised; illness perception was rated using the Brief Illness Perception Questionnaire; self-efficacy was measured with the Generalized Self-Efficacy Scale; and self-esteem was measures with the Rosenberg Self-Esteem Scale. The test-retest reliability, predictive validity and concurrent validity of this tool were established by Broadbent et. al. (2006). The research found women with MS had higher reported self-management skills than men with MS and that individuals with higher education levels had higher selfmanagement scores. An important finding in this study was there is no significant 
correlation between Expanded Disability Status Scale (EDSS) and self-management. Wilski and Tasiemski (2015) found that younger patients had higher scores on selfmanagement outcomes.

The EDSS is a 10-item ordinal scale reporting overall disability in MS. The scale ranges from 0 (normal neurologic function) to 10 (death from MS) and is reported in half-point increments. The EDSS is geared towards ambulation, reporting heavily on use of assistive devices or wheelchairs. (Kurtzke, 1961; Kurtze, 1983). One critique of the EDSS is that is lacks sensitivity towards mild changes in function or functional changes not related to ambulation, and has limited interrater reliability. (Noseworthy et. al., 1990).

Wilksi and Tasiemski (2015) also investigated the effect of personal factors on self-management in MS. Findings suggested that patients with higher educational levels scored higher in self-management, and women typically scored higher in selfmanagement than men. "The study participants who presented with higher general selfefficacy, long timeless perspective and perception that treatment can control progression of the disease tended to have higher self-management levels." (Wilski \& Tasiemski, 2015, pg. 5). Wilski \& Tasiemski (2015) found that improved self-efficacy resulted in increased physical activity, improved compliance in disease control and progression and higher self-management scores.

The importance of advocacy and self-advocacy has been described in the literature related to various patient populations. The National Coalition for Cancer Survivorship (NCCS) defines self-advocacy as the "continuum that begins when an individual is diagnosed with cancer" and stresses the importance of patients being heavily 
involved in decision making in regards to their treatment. (NCCS, 2004). The National MS Society defines self-advocacy as the "ability to effectively communicate an interest, desire, need or right - and negotiate to get it.” (National MS Society) In addition, the NCCS suggests patients "arm themselves with the tools and skills necessary to feel comfortable about asserting yourself and communicating clearly about your cancer care needs." (NCCS, 2004). In their guide to becoming a self-advocate, the NCCS discusses how disease and treatment self-education promote self-advocacy. Additionally, the NCCS identifies changes in the modern healthcare system that requires patients to be more active as advocates, including increased healthcare costs, limited referrals, staffing shortages and strict reimbursement policies. The NCCS also described self-advocacy benefits: decreased stress and anxiety, improved confidence, improved quality of life, collaboration with peers and emotional support. There are four primary components of self-advocacy: information-seeking, communication, problem-solving and negotiation. (NCCS, 2004). In patients with MS, there is potential for cognitive or communication barriers that may affect an individual's ability to effectively advocate for themselves.

The National MS Society describes effective self-advocacy as awareness of strengths and needs, ability to identify individual goals, and understanding of legal rights and responsibilities. In addition, the National MS Society describes effective practices for self-advocacy as situational needs assessment, consideration of ideal solutions, identifying assistance and using an organized approach. In these practices, there may be limitations for patients with MS because of psychological and cognitive impairments. Cognitive impairments that may affect patients with MS include short term memory problems, difficulty with information processing, impaired attention and impaired 
executive functions. Prevalent psychological factors affecting patients with MS include depression, anxiety, grieving, coping issues and emotional problems.

Brashers et. al. (1992; 1999) described three critical components of self-advocacy in patient with HIV: self-education, increased assertiveness, and mindful nonadherence. Mindful nonadherence refers to the ability of a patient to make responsible decisions when providers' recommendations are not followed and to reject a proposed treatment or treatment protocols outlined by the physician. Brashers et. al. found that patients that are better informed about diagnosis are more likely to be compliant with treatments, which can impact their long-term quality of life. They also found that assertive patients obtain more information about their diagnosis and are therefore more involved in healthcare decision-making.

Brashers et. al. (2009) designed and compared the Patient Self-Advocacy Scale (PSAS) in patients with HIV $(n=174)$ compared to healthy controls $(n=218)$ and assessed the reliability and validity of the measure. The PSAS is a patient-reported measure composed of 12 items on a 1 (strongly agree) to 5 (strongly disagree) Likert scale. The consistency of the PSAS was studied by comparing it to the Desire for Control Scale, the Health Opinion Survey Instrument (HOSI), the Desire for Autonomy Scale and the Health Locus of Control Scale. Reliabilities for the Desire for Control Scale were established by Reed (1989) and Smith et. al. (1984). The HOSI measures preferences for information seeking and behavioral involvement and reliability was established by Krantz et. al. (1980). Reliability for the Desire for Autonomy Scale was determined to be .78 in work completed by Ende et. al. (1989). The Health Locus of Control Scale measures 
internal or external locus of control and reliabilities were reported by Dahnke et. al. (1994).

The findings of these studies concluded that the PSAS is reliable and valid for measuring patient involvement in decision-making related to healthcare needs. Authors concluded that the importance of measuring self-advocacy is related to "increased healthcare participation and increased likelihood of nonadherence.” (Brashers, 2009).

Pickett et. al. (2012) studied educational offerings in the mental health sector to determine the effectiveness of an 8-week peer-led program, The Building Recovery of Individual Dreams and Goals (BRIDGES). This research cited the work of Brashers et. al. (1995) that described patients who lacked knowledge about their diagnosis were less likely to discuss their needs with healthcare providers and that many feel is it not appropriate to ask questions or challenge their providers. The goal of BRIDGES was to "empower mental health consumers by providing them with basic education about the etiology and treatment of mental illness, self-help skills and recovery principles, and peer support." (Picket et. al. 2012, pg. 421). This eight-site study had 428 patients with mental illness complete interviews prior to, at the conclusion and 6 months after the BRIDGES program. The BRIDGES program was taught in multiple formats including lecture, group participation and group discussion. The participants completed the 28item Empowerment Scale and an adapted version of the PSAS. (Brasher, et.al, 2009). Excellent reliability and validity of the Empowerment Scale were established by Rogers et. al. (2010). BRIDGES participants increased overall empowerment and empowerment-self-esteem and self-advocacy, specifically assertiveness scores when compared to the control group. Self-efficacy referred to the individual's confidence in 
ability to control the environment, self-advocacy is the ability to represent and express needs and wants. Self-esteem reflected a belief about one's own worth. These three attributes work together in effective self-management. At the 6-month follow-up interview scores on empowerment and self-advocacy were maintained and showed the lasting impact of this educational program. Limitations of the study are the lack of observed participant involvement and peer and group leader interaction.

\section{Cognitive Load Theory}

The cognitive load theory has become one of the most significant areas of educational research over the past two decades with a significant amount of literature developed since first described. (Paas et. al. 2010). The cognitive load theory describes situations in which learners are overwhelmed processing large amounts of information. The basis of cognitive load theory is that long term memory appears to be unlimited, whereas short term (or working memory) has limitations in both capacity and duration of time in which information can be stored. Long term memory is easily accessed and required to build on with new information. For learning to occur, working and long term memory must work together.

Working memory has the primary function of processing new information before it can be translated into the long-term memory. The estimated capacity for working memory is $4+/-1$ elements and the duration of storage of information is about 30 seconds. (Cowan, 2001). Information that is not stored or practiced within that 30second timeframe is not transferred to long-term memory. However, the limits of working memory are resolved when dealing with familiar information as compared to brand new information. 
The cognitive load theory was initially described to understand the limitations of learners' acquisition of new information. One critical component of the theory is that instructors cannot overload or overwhelm the working memory, otherwise it fails to accept new information and new learning cannot occur. (Paas, 2010). There are three essential components of the cognitive load theory: intrinsic load, extraneous load and germane load. Intrinsic loads are related to the complexity of the information to be learned. Extraneous load are caused by poorly designed educational programming, and germane load is the load of working memory that can handle intrinsic information. (Paas, 2010).

Another important component of the cognitive load theory is knowledge or information can be borrowed or learned from other people instead of always relying on personal experiences to create learning. The degree to which an individual attends to an educational task is highly associated with the structure of educational delivery. (Paas, 2010). Therefore, the design of delivery for educational programming must always be carefully considered.

Many researchers have identified potential strategies to manage the three aspects of cognitive load theory in attempt to improve working memory and overall learning. Instructional techniques focused on examining examples instead of active problem solving allows learners to function more in working memory and relate this information to known information within the long-term memory. Further recommendations include limiting intrinsic loads, which can potentially result in rapid overload of the working memory. Management of intrinsic load can be accomplished by initiating education with simple tasks and building from those. (Paas, 2010). 


\section{Coping, Cognitive and Psychological Impairments in MS}

In a study of 140 patients with MS using standardized mental health measures as defined by the DSM-IV, several common psychological diagnoses were identified. (Korostil, 2007). Anxiety was identified in $35.7 \%$ and generalized anxiety disorder was found in $18.6 \%$ of patients, with greater risk found in females and individuals with a history of depression. (Korostill, 2007). The work of Korostil and Feistein (2007) indicates that although psychological impairment is common in MS, these diagnoses are often overlooked by neurologists and go untreated, suggesting that many patients may be dealing with psychological dysfunction in addition to the recent diagnosis of a progressive neurological condition.

The work of Chwastiak et. al. (2002) investigated a large sample of people with MS and found $41.8 \%$ of patients had evidence of depression. Furthermore, the risk of depression across the lifespan was estimated to be 50\%. (Chwastiak et. al., 2002). When comparing these findings to other chronic medical conditions including asthma, diabetes and epilepsy, the incidence of depressive diagnoses are more common in MS. (Kern, 2009).

Wineman et. al. (1994) studied 433 patients with MS and 257 patients with spinal cord injury (SCI) to evaluate coping behaviors specifically related to an individual's uncertainty about an illness and ability to cope with some degree of uncertainty. In this study, two factors of coping were identified: the emotion-focused coping (EFC) behaviors and the problem-focused coping (PFC) behaviors. (Wineman, 1994). Previous research by Folkman and Lazarus (1980) determined that EFC behaviors are more often used health-related stress, and PFC behaviors are more likely to be associated with work 
stress. (Folkman \& Lazarus, 1980). Patient vulnerability was a critical variable identified in the literature. Without vulnerability, there were significant differences found in the types of coping (EFC vs. PFC) used by patients. (Wineman et. al. 1994) Their research found that patients employ different types of coping when different types of situations occur, thus defining the need to teach multiple coping strategies to patients. Wineman et. al. states that "Clinicians need to be aware that under conditions of high illness uncertainty and appraisals of danger, the individual is at risk for negative emotional outcomes. (Wineman et. al., 1994, pg. 193). Illness uncertainty might be higher, if not at a peak, in patients that have recently been diagnosed with a disorder such as MS.

Sadovnick et. al. reported the incidence of depression in patients with MS to be about 50\%. Depression can be linked to cognitive impairments such as problems with attention, reasoning, executive functions, memory or judgment. Another study estimated the incidence of these cognitive impairments to be as high as 60-65\%. (Polman, et. al. 2006). However, there is not clear research to establish the specific cause of depression in patients. (Lynch, 2001). Lynch (2001) used a sample population of 188 patients with MS to measure psychological function using the following tests: Self-Rating Depression Scale (SDS), The Ways of Coping (WOC), the Hope Scale (HS) and the Uncertainty of Illness Scale (UIS). These results differed from a study by Mohr (1997) by noting insufficient findings linking coping as a intervening variable between disability and depression. Mohr (1997) found that patients with high impairment levels also had higher scores for depression, escape-avoidance coping and problem solving, while Lynch (2001) found correlations between impairment groups to be more similar. Lynch et. al. also 
reported that depression in patients with MS was not necessarily related to an individual's disability status, hypothesizing that patients of all levels of functionality are likely to experience depression. (Lynch, 2001). The biggest limitation of the research performed by Lynch et. al. is that it failed to define coping as a variable of depression and disability, which differs from the research by Mohr et. al. (Lynch, 2001).

Many studies have described the relationship between level of disability and incidence of depression. Mohr et. al. (1997) surveyed 91 patients with MS on various mental health measures, including depression using the Beck Depression Inventory, coping using the Ways of Coping Inventory (WOCI), and level of neurological impairments using the Expanded Disability Status Scale (EDSS). Participants were divided into groups based on level of impairment according to EDSS scale as determined by a neurologist. In this correlational analysis there were two possible outcomes to consider. The first model considered coping as a response to depression. In this model, treatment for depression may be indicated, as increased levels of neurologic impairment appears to produce depression. Therefore, treating the depression may allow for improved ability to utilize coping behaviors. An alternative hypothesis suggested that depression is a response to coping. In this example, "increasing neurologic impairment reduces one's adaptive coping abilities which results in a greater level of depression." (Mohr, 1997). For these individuals, treatment should likely focus on improving adaptive coping skills to decrease or manage depression. However, the authors suggest that these examples are not mutually exclusive, and that coping skills may affect psychological function and vice versa. Mohr also reported that patients with higher EDSS scores (defined as greater than 6.5) had increased prevalence of depression and utilized more 
avoidance behaviors in coping with their disease. Patients with EDSS scores less than 7.0 were associated with a lower prevalence of depression, but used more problemcentered strategies to cope with their diagnosis and disease progression. There were two significant limitations of this research: the lack of information on patient cognitive status and a low (46\%) response rate. Without prior knowledge of cognitive status, it would be difficult to determine whether those impairments are associated with depression and coping. The authors also recommend use of a depression-screening tool such as the Beck Depression Inventory, and noted that although providers tend to be aware of psychological problems in this patient population, early recognition was important in treatment. The significant of this research was that it suggested a correlation between significance of neurologic impairment and risk of depression. It also reported that patients with depression who are more advanced in their disease process are more likely to utilize maladaptive coping behaviors. (Mohr, 1997).

There is limited research that has specifically looked at psychological factors early on in the disease processes. Kern et. al. (2009) considered this time frame as being critical in terms of psychological issues affecting quality of life. In this study, psychological stress affecting health-related quality of life within the first three years since diagnosis of MS was studied. (Kern, et. al., 2009). Patients with MS were interviewed at 6-month follow-up appointments and EDSS scores were updated. Surveys completed during the interview included the Symptoms Checklist-90-Revised (German version) which is a self-reported measure to assess psychological distress in the following areas: obsessive-compulsiveness, interpersonal sensitivity, phobic anxiety, somatization, depression, anxiety, hostility, paranoid ideation and psychoticism. Participants also 
completed the Functional Assessment of Multiple Sclerosis Quality of Life (FAMS) scale, a 59-item self-reported quality of life measure. Kern et. al. (2009) reported on 31 patients within 36 months since diagnosis and compared to 24 healthy individuals on patient-reported outcomes of psychological distress and quality of life. Findings concluded that psychological distress was more prevalent in patients with MS as compared to healthy controls. There was also a negative correlation between EDSS scores and quality of life, specifically for mobility, contentment and emotional wellbeing. In patient-reported outcomes, individuals with a higher EDSS score reported lower quality of life. Furthermore, patients with relapsing-remitting MS reported increased somatization, obsessive-compulsiveness, interpersonal sensitivity, anxiety, paranoid ideations and psychoticism. Limitations of this work included the cross-sectional design for assessing the relationship between psychological stress, neurological disability and quality of life, which limited the ability to determine exact causality. In this study, the sample size was on 31 patients, which makes the results less generalizable. Additionally, the sample size was small and potentially biased, making the results less generalizable. This work confirmed the presence of significant psychological distress in early-stage MS as compared to healthy controls. It also defined psychological stress in early MS is not necessarily correlated with level of functional or neurological disability. (Kern, 2009). Smith et. al. (2000) also evaluated patients in early stages of MS and reported increased level of distress compared to healthy controls, suggesting that psychological distress is not necessarily related to the neurological disability but instead may be associated with the social and emotional demands associated with receiving a diagnosis of MS. (Smith, et. al., 2000). 
Some research exists that investigates illness perception in MS. Smith et. al. (2000) defined the effect of psychological distress on illness perception in MS. This work compared the perception of disability of a patient with MS and depression to the perception of disability their physician reported and compared to individuals that were not depresses. These researchers hypothesized that patients may have a negative perception of treatment effectiveness. (Smith, 2000).

The correlation between psychological impairment and employment status was been studied by Moore et. al. (2013). Their findings concluded that individuals with MS who left the workforce, decreased their workload by job modification or moved to parttime positions reported increased levels of disability when compared to individuals who continued with fulltime employment. Additionally, when job changes were made, those individuals also reported increased levels of fatigue, increased cognitive impairments and more mobility issues. (Moore, 2013). Other patient-reported issues were described related to cognitive impairments such as delayed processing and memory impairments. (Rumrill, 2015).

Emotional Intelligence (EI) has been defined as the "ability to manage feelings or emotions" and includes components such as perception, understanding and regulation of emotions. (Ghajarzadeh, 2014). In one study 166 patients with confirmed diagnoses of MS were compared to 100 healthy controls to evaluate the EI as a factor in MS. Results showed that EI scores were significantly lower in those with MS when compared to healthy controls, inferring that the disease may affect the ability of individuals to regulate emotions. This study also determined that EI was not significantly different in men and women regardless of the presence of MS. (Ghajarzadeh, 2014). 


\section{Guiding Contemporary Research}

The Cochrane Collaboration (2014) performed a comprehensive literature review on information provided to people with MS. Over 1300 patients in 10 different studies from the United States, Germany, the United Kingdom, Italy, Belgium and Australia were included in the analysis assessing various approaches to educational delivery. The age range for patients in these studies was 31-51 years old, and $60 \%$ of the participants were women. The conclusion of this analysis only presents low-moderate quality research indicating the need for additional studies in the area of education for people with MS.

The Cochrane Collaboration (2014) reviewed four studies (524 patients) that looked at understanding of MS, there were significant differences in patient knowledge following intervention. However, there is only moderate level research to support these studies based on the presence of bias.

An additional four studies assessing decision-making in patients with MS were analyzed with low quality research to support claims based on bias and inconsistency. The research by Kopke et. al. (2009) suggested there is a significant difference in a patient's ability to play an active role in decision making when provided with patient education. Two studies that showed no difference in decision-making or role preference in patients that were educated about their disease. (The Cochrane Collaboration, 2014).

Five studies analyzed in The Cochrane Collaboration (2014) assessed the effects of education in MS on quality of life. Two studies reported improvements in some of the sub-scales of the Short-Form 36 (SF36), a general scale used to assess quality of life in many patient populations. Both of these studies (Ennis, 2006; O’Hara, 2002) showed 
improvements in the mental health scale of the SF36 after providing patient education. However, both of these studies were low quality based on the presence of bias and inconsistencies as identified by the Cochrane Collaboration review.

The last outcome group assessed in the Cochrane Collaboration (2014) reviewed the frequency of adverse effects related to educational programming in patients with MS. Six studies were analyzed, including 765 patients, and no adverse events were reported.

Mulley et. al. described recent advances in medical interventions and the importance of physicians understanding all potential treatment options as well as associated risks, benefits or side effects. These authors also point out the flawed assumption that doctors are the experts and ultimately know best in terms of diagnosis and treatment. Mulley et. al. also discuss two types of diagnosis: the medical diagnosis, and the patient preference diagnosis, which is often silent. A preference misdiagnosis occurs when patients are given treatments that are not their first option, or when other options may not have been offered. These misdiagnoses also occur when patients perceive one treatment as being superior based on the notion that "physicians know best." A cross-sectional descriptive dissertation has been completed investigating the relationship between patient-related learned helplessness and disease status, functional disability, social disability and disease activity in MS. Learned helplessness is "a generalized expectancy of non-contingency between response and outcome" that patients with chronic illness are at high risk of developing. (McGuinness, 1995). Learned helplessness has been associated with poorer health outcomes and is indirectly associated with impairments of cognitive function, affective health and motivation. This dissertation study included 72 patients with MS in Canada who had been diagnosed for at 
least one year and recorded the Minimum Record of Disability, Kurtzke's Functional Systems and the Disability Status Scale, the Incapacity Status Scale, the Environmental Status Scale, the Learned Helplessness Scale and demographic data. Patients voluntarily completed these scales at the time of clinic appointments, or were visited to complete the measures. The study included 72 patients ( 50 female, 22 male), fifty percent of participants with at least some university education, and 34.7\% that were currently employed. (McGuinness, 1995).

The research concluded that there is a statistically significant correlation between learned helplessness and increased social disability, employment status and between disease status functional disability and social disability. The study found a weak positive but statistically non-significant relationship between disease status as rated on the Disability Status Scale and learned helplessness. This study concluded that patients with MS are susceptible to learned helplessness given the chronic nature of the disease. However, learned helplessness is likely to decrease with disease duration, suggesting patients learn to cope or manage the effects of their disease over time. Patients that are involved in disease management and effectively advocate for their needs may be less likely to experience learned helplessness, further providing support to the importance of promoting patient education and advocacy.

MS is a variable but progressive neurological condition that affects each individual differently, establishing the need for individualized education. The variability of the disease is indicative of the uncertainty patients experience in coping with the diagnosis of MS. Decision-making is a critical part of autonomy and management of MS and ranges from DMT to management of acute relapses and adjunctive therapies. The 
increasing number of available treatment options requires additional education and support from healthcare providers. There are multiple barriers to patient education in MS including cognitive impairments, access to education, ability to understand material, accuracy and timeliness of the delivery of education, and the cognitive load theory. There are several studies showing the importance of educational programs for patients and investigating the efficacy of various delivery styles. Providing accurate, timely and evidence-based education to patients with MS is a critical part of autonomy and selfmanagement. 


\section{CHAPTER 3 - METHODOLOGY}

\section{Introduction}

In the past two decades, research has shown the effectiveness of treatment options for patients such as disease-modifying therapies and the benefits of a multi-disciplinary approach to treatment in managing multiple sclerosis (Burks, 2000. Halper, 2010. Namey, 2010). However, many patients either live in areas where access to care is limited or they are not provided with the appropriate information to advocate effectively in managing their disease. There is no standard as to the optimal timing and amount of information to provide to patients after receiving a diagnosis of MS.

Treatment of MS includes medication management and monitoring of disease progression by a physician or nurse practitioner. There is also a significant amount of research to indicate the benefits of a multi-disciplinary approach of services and education from nursing, rehab experts, social workers, nutritionists, and mental health practitioners and others. Due to the wide range of clinicians involved in care, there is potential for education to be completed in various settings although there may be little to no communication between providers.

One of the challenges of caring for patients with MS in rural areas is the lack of access to specialty services. Larger healthcare systems often have expert clinicians and support staff available to participate in patient education. Here, a common educational model is offered to newly diagnosed patients to improve patient understanding of their diagnosis and be provided with strategies for disease management.

At Norton Healthcare, an educational program- titled MS 101 is offered quarterly in attempt to address the educational needs of patients with a new diagnosis of MS. The 
diagnosing neurologist encourages patients to attend the next available course following a definitive diagnosis of MS. However, depending on the timing and patient availability, several months or even years may pass before an individual attends this program. In other cases, patients may be attending the program within the first few weeks of diagnosis. In MS 101, an MS-specialist nurse navigator and a licensed marriage and family therapist provide the educational programming.

Topics in MS 101 include information about the pathology, medications (diseasemodifying and adjunctive therapies), relapses vs. pseudo-relapses, signs and symptoms, the disability process, employment issues and an introduction of the medical and support teams. The course is approximately four hours long with intermittent breaks.

Some barriers that arise in education is patient cognitive load, (the ability to absorb large amounts of information), and possible cognitive impairments in patients with MS. Ultimately, patient education in chronic, progressive conditions is critical and provides patients with the ability to empower themselves, improve their quality of life and ensure optimal medical management.

\section{Statement of the Problem}

There are a wide variety of educational models offered to patients with MS. This has led to patients either being given too much, too little or poorly timed information in relation to their needs. Sweller et. al. $(1998,2993,2004,2005)$ has shown that the cognitive load theory plays an important part in understanding what people can absorb and retain at any given time. In patients with a neurologic disease, there is also potential that cognition may play a role in optimal timing, amount and pedagogy of patient education. This may lead to patients not understanding the information they are being 
presented, or not being able to process the large volume of information that is bring provided.

Self-advocacy is an important part of patient education. Optimally, patients should be able to advocate for their healthcare needs and have better control of the disease process, which improves the quality of life. This research study aims to provide guidelines to optimize educational programs developed for patient understanding, selfadvocacy, quality of life and functional outcomes.

\section{Research Questions}

Research Question 1: How does the timing of patient education affect self-advocacy in patients with MS?

Research Question 2: How does the amount of information provided to patients with MS impact their self-advocacy?

Research Question 3: What demographic information correlates with self-advocacy?

Research Question 4:What are the optimal time frames in which diagnosis education should occur?

Research Question 5: How much information can patients with a progressive neurologic condition absorb in the acute phase of diagnosis?

\section{Hypotheses}

H1 (Null): There is no relationship between the timing of education and patient selfadvocacy.

H1 (Alternate): There is a relationship between the timing of education and patient selfadvocacy.

H2 (Null): The amount of education has no impact on self-advocacy. 
H2 (Alternate): The amount of education provided negatively impacts self-advocacy.

H3 (Null): There is no correlation between demographics and patient reported selfadvocacy.

H 3 (Alternate): There is a correlation between demographics and patient reported selfadvocacy.

H4 (Null): There is no correlation between timing of patient education and selfadvocacy.

H4 (Alternate): There is a correlation between the timing of patient education delivery and self-advocacy.

H5 (Null): There is no relationship between the amount of information provided to patients and reported self-advocacy.

H5 (Alternate): There is a relationship between the amount of information provided to patients and reported self-advocacy.

\section{Population and Sample}

This study will use volunteers from the Norton Healthcare system neurology department as subjects. All patients diagnosed with MS at Norton Healthcare have opportunities to attend the MS 101 courses. Patients involved with the Norton Neurologic Resource center or receiving therapies at the Norton Neurosciences \& Spine Rehabilitation Center are also encouraged to attend by therapists. MS 101 is offered in May, August and November in 2016 so patients will have the opportunity to attend a convenient course. All participants will be over the age of 18 at the time of diagnosis. The ability to recruit patients will be impacted by the number of diagnoses made in the 
recruitment window, but the sample size goal is 30 individuals. Typically, each MS 101 course has about 5 attendees.

Eligibility criteria for this study were: (a) confirmed diagnosis of MS, (b) ability to sign informed consent, (c) attendance at MS 101 course at Norton Healthcare during the data collection period. Only patients who do not wish to participate will be excluded. Patients requiring assistance will be permitted to use family, caregivers, support staff or a researcher to complete surveys.

IRB approval was obtained through the University of St. Augustine on March 31, 2016 with permission from Norton Healthcare. Patient confidentiality was maintained throughout the study in accordance with all Health Insurance Portability and Accountability Act (HIPAA) to protect patient privacy. Informed consent was reviewed with each participant and signed prior to the start of the MS 101 program.

The MS 101 course is a four-hour program offered quarterly at Norton Healthcare for patients and families/caregivers diagnosed with MS within the past two years. A nurse navigator and a licensed family and marriage therapist teach the course, each covering their areas of expertise. Material to be covered in the course includes MS pathology and pathophysiology, symptoms, disease-modifying therapies, adjunct treatments, the multi-disciplinary team, relapses and pseudo relapses, coping and depression, and work and family issues. An MS research coordinator visits briefly to introduce the research team and describe current studies, and provides contact information should patients wish to get involved in clinical trials. A representative from the MS Society provides literature and contact information to patients. The course is given to small groups with PowerPoint presentations and handouts. 


\section{Instrumentation}

The Patient Self-Advocacy Scale (PSAS) was selected as a self-advocacy outcome measure based on its extensive use in the literature for patients with cancer and Human-Immunodeficiency Virus (HIV) or Acquired Immune Deficiency Syndrome (AIDS). The PSAS assesses assertiveness in healthcare decision-making, illness, treatment education and healthcare interactions. (Brashers, 1999). It is a patientcompleted 12-item questionnaire reported on a 5-item Likert scale ranging from strongly agree to strongly agree.

Validity and reliability of the PSAS was reported by Brashers et. al. (1999) using a sample of 218 patients with HIV-AIDS. Sample group 1 included 174 patients; sample group included 218 healthy controls recruited by convenience. The combined sample was given an 89-item questionnaire that included random placement of the 12 PSAS items. The PSAS scores were tested for validity by comparison with the Desire for Control Scale (Burger, 1992), the Health Opinion Survey Instrument (HOSI: Krantz et. al., 1980), the Desire for Autonomy Scale (Ende et. al., 1989) and the Health Locus of Control Scale (Dahnke et. al.,1994).

Reliability for sample group 1 was 0.60 for education, 0.67 for assertiveness, 0.82 for nonadherence and 0.78 overall, calculated using Cronbach's alpha. Reliability for sample group 2 was 0.61 for education, 0.69 for assertiveness, 0.7 for nonadherence and

0.78 overall. Reliability of the combined sample was reported as 0.64 for education, 0.70 for assertiveness, 0.79 for nonadherence and 0.78 overall.

Validity was assessed by use of construct and criterion measures, including patient reported participation in activist groups compared to those not involved in activist 
groups. Construct validity was confirmed with comparison of other measures including the Desire for Control Scale and HOSI.

Additional demographic information was collected, including age, gender, race, marital status, household income, education level, history of previous MS education, date of diagnosis and occupation. This information was collected for correlational analysis.

\section{Data Collection Procedures}

As patients arrived to the MS 101 program, the primary researcher introduced herself, explained the project and inquired if patients were willing to participate. It was explained that participation was completely voluntary. If agreeable, the consent form was reviewed and signed by the participant, the researcher and a witness (staff from the Norton Resource Center). Due to the small number of participants in the programs, consent forms were reviewed individually with each participant. Pre-course PSAS surveys, demographic forms and consent forms were collected prior to the start of the program. Post-course surveys were handed out at the conclusion of the program and immediately collected by the researcher when completed. The researcher transported all research materials to a secure office at Norton Healthcare for storage.

\section{Procedure}

Patients will be recruited for the MS 101 course as part of the standard of care at Norton Healthcare. Patients are encouraged to attend at diagnosed and subsequent medical appointments with the neurologist. Additional recruitment may occur from support staff in the physician practice or the Norton Neurologic Institute Rescore Center (NNIRC), where the MS Nurse Navigator, mental health, social and lay navigators are located. Patients sign up for MS 101 course in advance by registering with the NNIRC 
staff who run the program. Upon arrival to the program, each individual will be asked if they wish to participate, and the consent will be reviewed and signed at that time. The patient will complete the demographic form and the PSAS prior to the start of the program. They will be asked to repeat the PSAS at the conclusion of the four-hour program. Patient information will be encoded to protect patient confidentiality and for data analysis purposes. Coding in Microsoft Excel will include: gender (male - 1, female $=2$ ), marital status ( single $=1$, arried $=2$, divorced $=3$, widowed $=4$ ), previous MS education $($ no $=1$, yes $=2)$, ethnicity $($ Caucasian $=1$, African American $=2$, Hispanice $=$ 3, Other $=4$ ), known family members with MS (no = 1, yes = 2), formal education level (middle school $=1$, high school graduate $=2$, vocational school graduate $=3$, some college $=4$, bachelors $=5$, masters $=6$, doctorate $=7$ ), current employment status (full time $=1$, part time $=2$, unemployed $=3$, retired $=4)$ and household income $(<\$ 25 \mathrm{k}=1$, $\$ 25-50 \mathrm{k}=2, \$ 50-100 \mathrm{k}=3,>4100 \mathrm{k}=4)$. PSAS items were coded for data analysis as follows: strongly agree $=1$, somewhat agree $=2$, agree $=3$, somewhat disagree $=4$, strongly disagree $=5$. All research materials will remain in the possession of a researcher and will be locked in a storage drawer that only the researcher has keyed access to. The drawer will be contained in a locked office at Norton Healthcare.

\section{Data Analysis}

Data analysis will be completed using the Statistics Package for Social Sciences (SPSS). Means will be calculated for age, time since diagnosis and additional demographic data. This study is a correlational quantitative research design.

\section{Dependent Variables}


The dependent variable is what the study presumes to be affected by the independent variable. In this study, the dependent variables will be 1) the patient's perception of their abilities as a self-advocate; 2) the amount of information retained from post-diagnosis educational programs.

\section{Independent Variables}

The independent variable is the component that is being manipulated by the study. In this instance, the independent variable is the timing and amount of education being provided to these patients. Patients will be coded for data processing including male $=1$, female $=2$. Other demographic information will be recorded including marriage status, previous formal education about MS, education level, family history of MS, ethnicity, employment, household income and occupation.

Descriptive statistics will be completed for mean, standard deviation, range for all demographic information. When appropriate, this data will be reported in percentages. The $\mathrm{P}$ value $<0.5$ will be used to support alternate hypotheses. Pearson correlation coefficient will be utilized to examine relationships between pre-PSAS scores and ages, and pre-PSAS scores and amount of formal education. Dependent samples t-testing will be utilized to examine the relationship between pre and post overall scores, while also reporting a standard deviation and standard error. Spearman's rho calculations will be processed to assess for any correlation between education level and changes in pre versus

post testing scores can be identified. An additional Spearman's rho will be calculated to assess and statistically significant changes between pre and post PSAS scores when compared with the time period since diagnosis. 


\section{Confounding Variables}

The potential for a multi-center may result in various instructors, which could be a confounding variable. The potential for variation in the number of patients being diagnosed and their ability to attend educational programs based on dates, times and location would be additional confounding variables. There is potential for variation in instructors of the programs, and potential for varying sizes of the programs, both of which may be viewed as confounding variables that may affect patient-reported data.

Additional confounding variables would include psychosocial factors and individual comorbidities. Issues such as anxiety and depression are common in individuals with MS and these factors might impact motivation and engagement in educational programming. Support from family members could play a role in individuals attending or their motivation for attendance at MS 101 courses. There is potential that individuals were unable to attend programming without encouragement from caregivers or support for transportation or other psychosocial needs.

\section{Ethical Issues}

During review of the consent forms, the researcher explained that there are no direct benefits of participation to each patient but that the overall goal was to make recommendations for future educational programs. It was also explained that the researcher is completing this project as a dissertation project for a doctorate in education at the University of St. Augustine. The researcher disclosed that she was employed by Norton Healthcare as a physical therapist in the neurologic institute. There was the potential for participants to feel pressured to participate based on the presence of experts in the field and the introduction of the researcher as a member of the MS team. It was 
reiterated that participation in voluntary and disclosed that physicians would not be aware of participation to dissolve any concerns about participation affecting care. The researcher also reviewed the coding procedure to protect patient identify if enrolled in the study.

\section{Limitations and Delimitations}

One potential limitation of this study is the potential sample size. Subjects will be recruited through the neurology department, but will rely on the number of diagnoses made during the time frame for data collection. Other limitations include the location and times of the educational programs, which may not be accessible or convenient to all potential subjects. If follow-up data is to be collected, there is potential that individual could relocate, leave the practice or choose not to participate in this portion of the study and would therefore limit long-term data collection. 


\section{CHAPTER 4 - RESULTS}

\section{Introduction}

The study outlined here was quantitative and utilizes primarily descriptive statistics with inferential statistics to make predictions about the population studied. All descriptive and inferential statistics were analyzed using the Statistical Package for Social Sciences (SPSS, 2016). The alpha level for rejecting the null hypothesis was established at the .05 probability level and all statistics reported are two-tailed unless otherwise specified. Over three MS 101 courses, a total of 11 participants were enrolled in this study.

\section{Study Participants' Demographics}

Demographic data for the eleven participants was collected to analyze relationships between demographics characteristics and pre- or post PSAS survey scores. Demographic data is reported in tables and described below.

Table 4.1 shows the ages of participants in the MS 101 courses from May 2016 November 2016. The average age was 42.55 years, with the youngest participant being 30 years old and the oldest at age 67.

Table 4-1. Descriptive Statistics for Age of Study Participants Variable

\begin{tabular}{llll}
\hline & $n$ & $M$ & $S D$ \\
& & & \\
\hline Age & 11 & 42.55 & 10.17 \\
\hline
\end{tabular}


Table 4-2 shows results from demographic data regarding marital status. Eight of the participants were married, two reported being single and one reported being divorced. Table 4-2. Descriptive Statistics Marital Status of Study Participants

\begin{tabular}{ccc}
\hline & Frequency & Percent \\
\hline Single & 2 & 18.2 \\
Married & 8 & 72.7 \\
Divorced & 1 & 9.1 \\
Total & 11 & 100.0 \\
\hline
\end{tabular}

Table 4-3 shows the number of children each participant has. Four patients do not have any children, three participants have one child, two participants have two children and one participant has 5 children.

Table 4-3. Descriptive Statistics for Number of Children of Study Participants

\begin{tabular}{ccc}
\hline & Frequency & Percent \\
\hline No Children & 4 & 36.4 \\
One Child & 3 & 27.3 \\
Two Children & 2 & 18.2 \\
Three Children & 1 & 9.1 \\
Five Children & 1 & 9.1 \\
Total & 11 & 100.0 \\
\hline
\end{tabular}

Table 4-4 shows that 10 of the 11 participants were Caucasian, and the other being African American. 
Table 4-4. Descriptive Statistics for Race of Study Participants

\begin{tabular}{ccc}
\hline & Frequency & Percent \\
\hline Caucasian & 10 & 90.9 \\
Black & 1 & 9.1 \\
Total & 11 & 100.0 \\
\hline
\end{tabular}

Table 4-5 reports the number of participants who have known family members with MS, which was one of the 11 participants or $9.1 \%$ of the sample size. This information is of particular interest given the known genetic component of MS as previously discussed.

Table 4-5. Descriptive Statistics for Family Members with MS

\begin{tabular}{ccc}
\hline & Frequency & Percent \\
\hline No & 10 & 90.9 \\
Yes & 1 & 9.1 \\
Total & 11 & 100.0 \\
\hline
\end{tabular}


The highest level of completed formal education was collected from each participant and results are shown in Table 4-6. The goal of collecting this data was to correlate changes in self-advocacy and pre- and post survey results based on education levels. All participants in the study had completed high school, with two completing some college education, three completing a bachelor's degree, three completing a master's degree and two with doctoral degrees.

Table 4-6. Descriptive Statistics for Level of Education of Study Participants

\begin{tabular}{ccc}
\hline & Frequency & Percent \\
\hline HS Grad. & 1 & 9.1 \\
Some College & 2 & 18.2 \\
Bachelors & 3 & 27.3 \\
Masters & 3 & 27.3 \\
Doctorate & 2 & 18.2 \\
Total & 11 & 100.0 \\
\hline
\end{tabular}


Employment status was collected to evaluate whether or not participants were working at the time of the MS 101 courses and if so, employed on a full time or part time basis. This is reflected in Table 4-7. Employment status is relevant for patients with MS as the disease is known to affect an individual's ability to maintain full time employment long term. Of the eleven participants in this study, 10 were working full time at the time of participation in the MS 101 course. One participant reported they were retired at that time.

Table 4-7. Descriptive Statistics for Employment Status of Study Participants

\begin{tabular}{ccc}
\hline & Frequency & Percent \\
\hline Full Time & 10 & 90.9 \\
Retired & 1 & 9.1 \\
Total & 11 & 100.0 \\
\hline
\end{tabular}

The average household income was assessed and is reported in Table 4-8. One participant $(9.1 \%)$ reported the household income of less than $\$ 25,000$ per year, most $(63.6 \%)$ reported household income between $\$ 50,000-\$ 100,000$ annually, and three participants $(27.3 \%)$ reported household income of over $\$ 100,000$ per year. 
Table 4-8. Descriptive Statistics for Household Income of Study Participants

\begin{tabular}{ccc}
\hline & Frequency & Percent \\
\hline$<25 \mathrm{k}$ & 1 & 9.1 \\
$50-100 \mathrm{k}$ & 7 & 63.6 \\
$>100 \mathrm{k}$ & 3 & 27.3 \\
Total & 11 & 100.0 \\
\hline
\end{tabular}

\section{Central Hypothesis Number One}

Descriptive statistics for pre- and post PSAS scores for each survey item are described Table 4-9. Of interest are changes between the pre- and post survey scores on each item. Increased numeric values indicate improved subject perceived ability for selfadvocacy. Scoring of the PSAS was coded as $1=$ strongly agree to $5=$ strongly disagree). The mean score for PSAS item 1 was 1.09 both pre and post showing that there was no change in scoring for that survey item. Survey item 1 asked about the participant's perceived belief that it is important to be educated on their health and diagnosis. Item 2 showed an increase in mean from 1.64 pre MS 101 course to a mean score of 1.73 post MS 101 . This survey item asked how likely a participant is to actively seek our information about their health. Increased scores here may indicate that patients may be slightly less likely to seek out information about their diagnosis following the MS 101 course.

Item 3 on the PSAS had a mean scored of 2.18 pre course and a post course mean of 2.00 showing a decrease of 0.18 . This survey item asked if the patient feels they are more educated than the typical United States citizen about health. The decreased score 
suggests there are slightly increased feelings of being more educated than the typical U.S. citizen about their health following this educational program. Item 4 had a pre course mean of 3.73 that decreased to 2.55 post course. This survey item asked participants about their knowledge of health-related problems; the decreased score of 1.18 suggested an improved sense of understanding their condition.

Item 5 had a pre-course mean of 3.55 that decreased to 3.0 in post-course surveys. Survey question number 5 inquires about a participant's assertiveness with their physician and perception of needs being met by their physician. Decreased scores suggests that patients at the end of the MS 101 course felt slightly more likely to act with assertiveness during discussions with medical providers.

Item 6 had a pre course mean of 2.91 that decreased to 2.64 post course. This survey item asked if the participant perceived that they are more or less assertive than most US citizens in terms of their healthcare needs. The decreased score here suggested that participants felt more assertive following the educational program.

Item 7 had a pre course mean of 3.00 and post course mean of 3.00, indicating no change in average scores on the survey item about the patient's ability to make suggestions to their physician about their healthcare needs.

Item 8 had a pre course mean of 1.55 and a post course mean of 2.64 suggesting that participants were less likely to question physicians about recommendation they did not agree with following the educational program.

Item 9 assessed whether or not participants felt that there were good reasons not to follow the physician advice. The mean score was unchanged between pre- and post surveys. 
Item 10 asked if participants felt they had a better grasp on what their needs were than their physician. In pre course surveys, the mean score for this item was 3.64, which decreased to 3.45 in post course analysis. The change in scores here suggests that patients generally felt that their awareness of their needs increased following the MS 101 program.

Item 11 asked if the participant was likely to follow physician advice even if they did not agree with the advice. In pre course surveys, the mean score was 2.91 which increased to 3.64 in post course surveys. This change in score suggested that patients were more likely to advocate for their beliefs following the education program when in disagreement with their physician.

Item 12 asked how often participants were noncompliant with physician recommendations. On pre course surveys, the mean score was 3.73 which decreased to 3.27 in post course analysis. This change in score suggests individuals were less likely to not comply with physician recommendations after the education program compared to previous understanding. 
Table 4-9. Descriptive Statistics for Pre and Post PSAS Scores

Pre PSAS

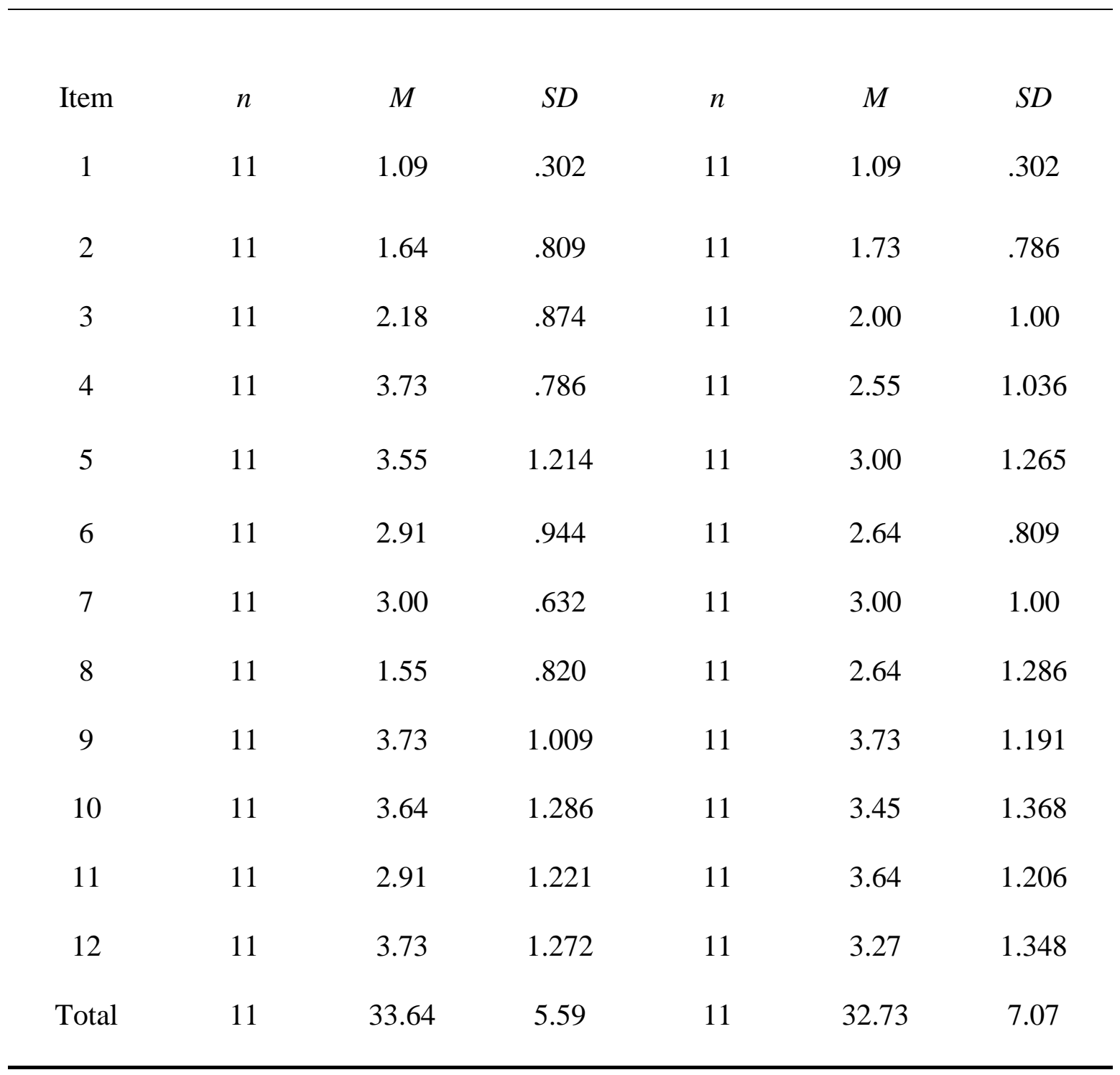


The central null hypothesis of this research project was that the differences between mean aggregate PSAS posts scores when compared with mean aggregate PSAS pre scores would show a decrease in overall scores suggesting improved self-advocacy. The alternative hypothesis was that post PSAS would be statistically superior. In conducting a paired samples t-test of the difference between pre and post measures the difference was not statistically significant, $t(10)=.756, p=.467$. We are unable to reject the null hypothesis (See Figure 4-1 below).

Figure 4-1. Bar Chart Pre/Post PSAS Scores

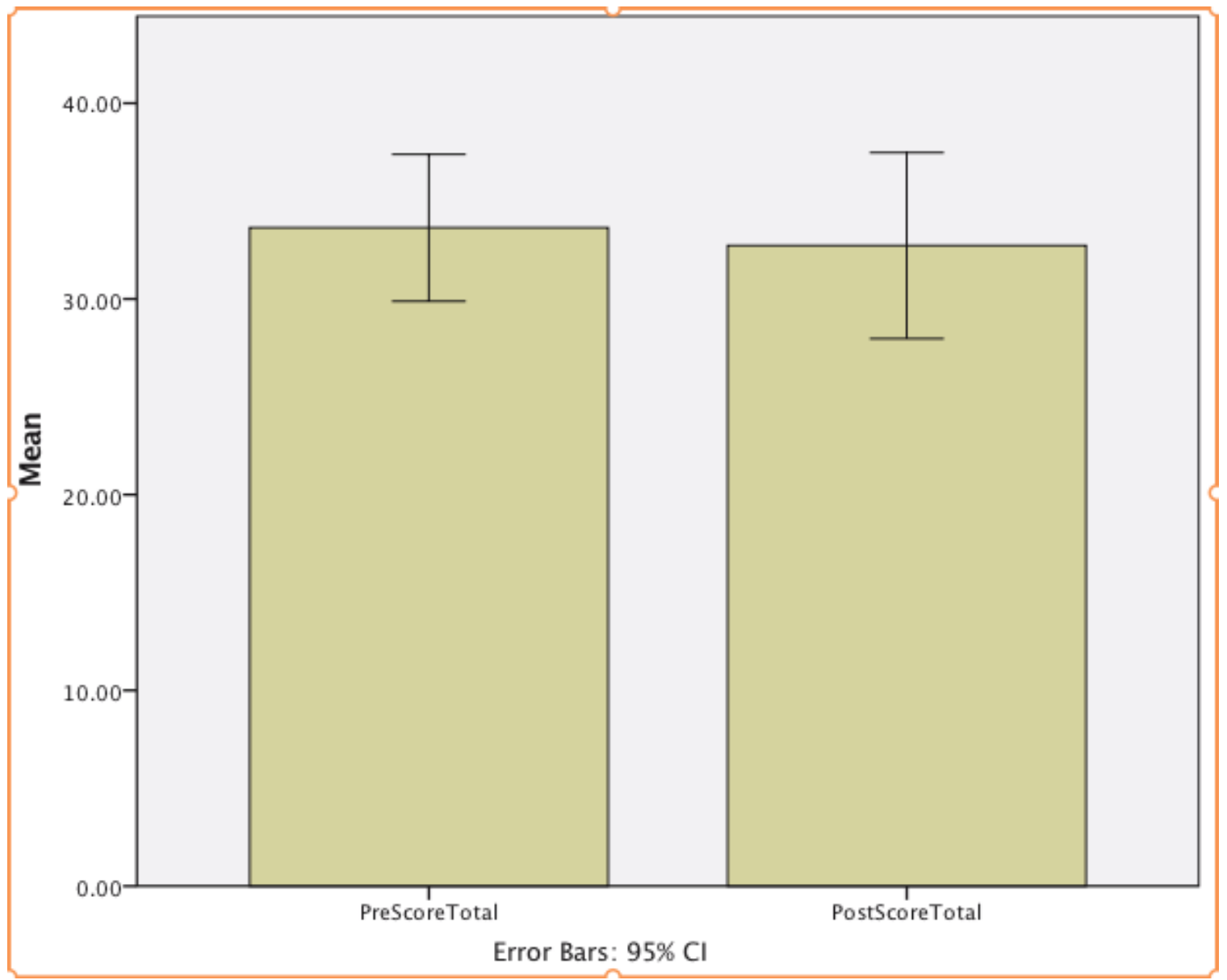




\section{Central Hypothesis Number Two}

It was hypothesized that the interval between time from confirming diagnosis of MS and receiving the MS 101 instructional intervention would be inversely, and statistically significantly related, to participant improvement scores in the PSAS measure. To test this hypothesis, subtracting participant's post PSAS measure from their pre PSAS measure created a difference score (hereinafter called Pre/Post Change).

Table 4-10 shows grouping of participants based on the time elapsed between confirmed diagnosis of MS and time of attending the MS 101 course. The majority of participants $(54.5 \%)$ had been diagnosed at least one month prior to the program, but no more than 3 months prior. Two participants (18.2\%) attended the program within the first 30 days since being diagnosed. Two participants (18.2\%) attended more than six months after being diagnosed.

Table 4-10: Descriptive Statistics Interval from Discharge of Study Participants

\begin{tabular}{ccc}
\hline & Frequency & Percent \\
\hline 1-3 Months & 2 & 18.2 \\
3-6 Months & 1 & 54.5 \\
> Six Months & 2 & 9.1 \\
Total & 11 & 18.2 \\
\hline
\end{tabular}


It is not reasonable to assume that time interval from diagnosis was normally distributed so a Spearman's Rank Order correlation was performed between interval and the Pre/Post Change score.

Figure 4-2. Scatter Plot of Relationship between Interval and Pre/Post Change Score.

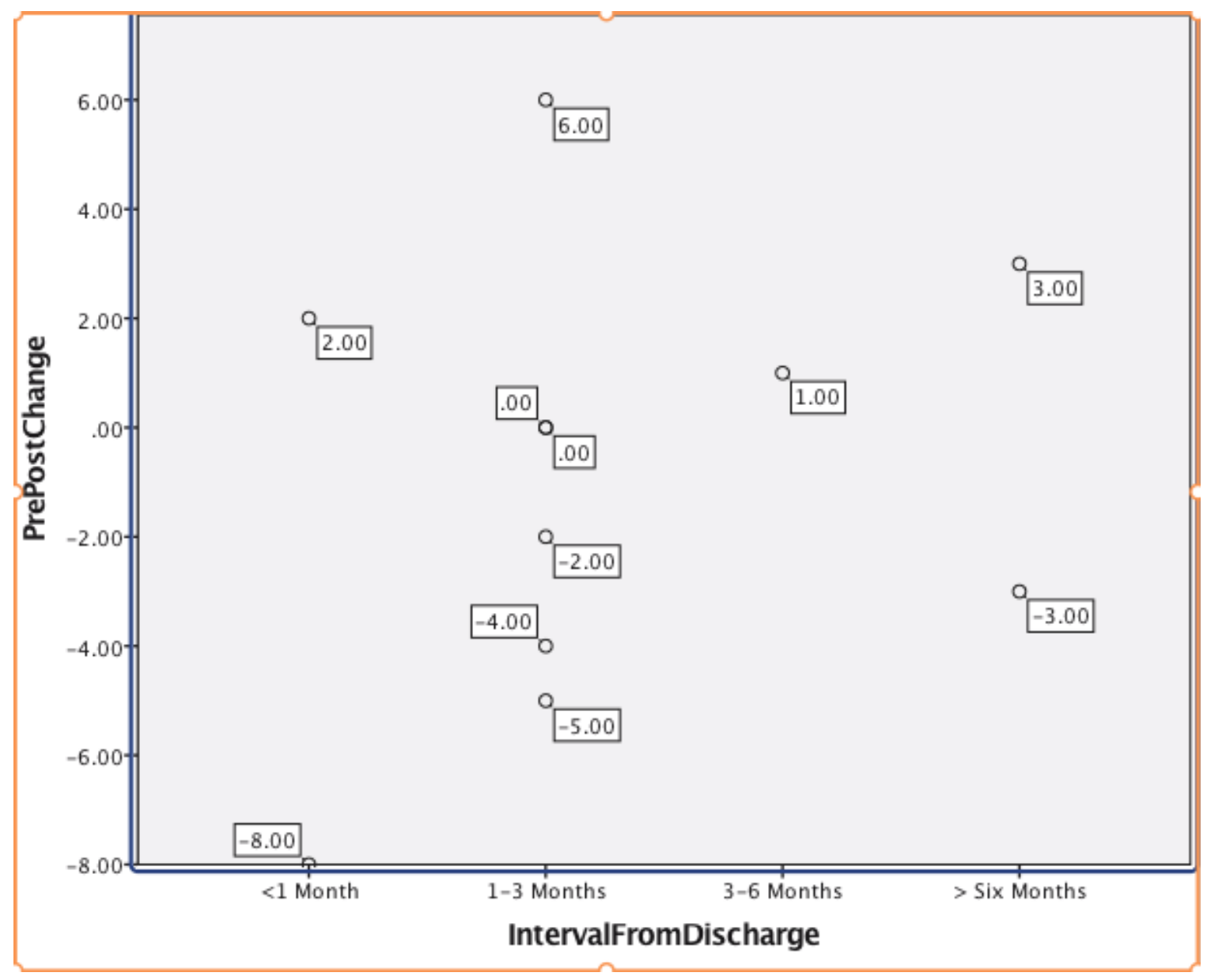


As discerned from the correlation matrix in table 4-11, the Spearman Rho correlation was positive in its direction (as opposed as negative as hypothesized), however, this relationship was not statistically significant. We are therefore unable to reject the null hypothesis that the impact of the instructional intervention was negatively correlated with improvement in PSAS score.

Table 4-11: Spearman rho Correlation between Interval from Diagnosis and Pre/Post Change Score

\begin{tabular}{ccc} 
& Interval From & Pre/Post Change Score \\
& Dx & \\
Interval from & 1.00 & .250 \\
Dx & & \\
Sig. (2-tailed) & & .229 \\
$\mathrm{~N}$ & & 11 \\
\hline
\end{tabular}

\section{Secondary Analysis}

Table 4-12: Pearson Correlation between Pre Score Total and Age

\begin{tabular}{ccc}
\hline & Pre Score Total & Age \\
Pre Score Total & 1.00 & -.107 \\
Sig. (2-tailed) & & .754 \\
$\mathrm{~N}$ & & 11 \\
\hline
\end{tabular}

Table 4-12 shows a Pearson Correlation between the total PSAS score from precourse and age. The Pearson Correlation was -.107 suggesting no correlation between these items. 
Table 4-13: Spearman rho Correlation between Pre Score Total and Education

\begin{tabular}{ccc}
\hline & Pre Score Total & Education \\
Pre Score Total & 1.00 & .061 \\
Sig. (2-tailed) & & .859 \\
$\mathrm{~N}$ & & 11 \\
\hline
\end{tabular}

Table 4-13 compared pre-course PSAS scores with the amount of participant education level. The Spearman's rho correlation coefficient here was .061 showing no significant correlation. In table 4-14 the Spearman rho correlation between post-course PSAS totals of 0.187 showed no education level correlation. 


\section{CHAPTER 5 - CONCLUSIONS AND RECOMMENDATIONS}

Gallien et. a. (2014) discussed the importance of a collaborative approach to the treatment of MS. The MS 101 courses provided in this report reinforced this by presenting the multidisciplinary team and providing education about the role of each team member. The collaborative approach was further promoted by the co-teaching of the MS 101 course by a registered nurse who specializes in the treatment of individuals with MS and a licensed clinical social worker (LCSW) who is part of the MS team. One outcome of Gallien's research was the importance of educating patients on each provider's role in care to better facilitate the relationship between patients and each member of their care team. As part of the information in the MS 101 course, the entire multidisciplinary team was introduced to patients and their roles defined. Handouts were provided with pictures and contact information of providers to assist with patient communication needs.

Multiple researchers including Bishop and Frain (2007, 2011), Fraser (2009) and Holman (2004) have discussed the effectiveness of educational programs in management and treatment compliance with progressive conditions. These researchers also noted that patient education near the time of diagnosis is a critical component in assisting patients in becoming active participants in their care and decision-making related to their care. The work of these researchers coincides with the goals of this study, which were to identify optimal timing for delivery of information given the known importance of education.

Bishop and Frain $(2007,2011)$ identified five components of MS-specific selfmanagement abilities. One of these components, treatment adherence and barriers was assessed in PSAS item number 12 which determined how frequently patients were likely to not comply with physician recommendations. Pre-course average scores were 3.73 
which decreased to 3.27. Although not a statistically significant change, it suggested a trend that patients were likely to comply with physician's recommendations. PSAS item number 11 is also relevant to this question. Here, participants were asked how likely they were to advocate for their beliefs or question their provider if they did not agree with recommendations that were made. Pre-course averages of 2.91 increased to 3.64 postMS 101 courses. This trend suggests that following formal education, patients were more likely to advocate for their beliefs or to question the provider when in doubt about the care that was recommended. Although not a statistically different change, this trend again suggests that patients may be more likely to advocate for themselves once educated about their diagnosis.

Bishop \& Frain's work also addressed understanding and active learning about medical conditions, which was also a part of this study. All participants voluntarily elected to attend MS 101 with the goal of better understanding and learning more about the condition. Two aspects that were not measured in this study was competency or retention of the information presented. Further research should identify the patient's baseline knowledge of MS, and compare to post MS 101 knowledge and retention over an extended time period. Formal assessment of pre/post understanding of MS would ensure type and quantity of information that is gained from one course.

An additional component of Bishop \& Frain's $(2007,2011)$ work was the level of active participation in decision-making. This was assessed in PSAS item number 5 which measured assertiveness when discussing care with providers. The average precourse score of 3.55 decreased to 3.0 following education. This trend implied that 
patients were more likely to be assertive after educational programming, a finding that is supportive of research of Bishop and Frain.

The last component of Bishop \& Frain's $(2007,2011)$ five components of selfmanagement was how patients managed the impact MS has had on their life. Although not objectively measured, this topic was covered in the MS 101 course. The LCSW addressed disclosing the diagnosis to friends and family and issues with employment in the MS 101 course. There were no specific measures obtained in this study to assess how MS has impacted the lives of patients, offering an opportunity for future research.

Bishop et. al. (2009) identified that most patients sought information from was the internet, books, physicians, support groups and MS societies. In this study, no patients reported receiving any prior MS education, which implied that they may prefer this course which was led by an MS-certified nurse and licensed clinical social worker who practiced as a mental health therapist for patients with MS, which is in agreement with Bishop's work. However, additional questioning about previous independent education about MS might be helpful to determine how much patients had read online or researched on their own.

Somerset (2002) had reported previously that patients preferred to receive education from MS-certified nurses. This study found that attendance at MS 101 courses supported the idea that patients at Norton Healthcare also preferred to receive education from MS-certified nurses. Patients had elected to attend this course and many had waited a few months in order for this to be their primary means of education. Patients at Norton Healthcare are informed about the MS 101 course by the neurologist or the Norton Resource Center which sponsors the educational programs. Matti et. al. (2010) described 
the preference of patients for education from neurologists or specially trained staff instead of primary care physicians or lay people.

Forbes et. al. (2007) described that patient needs for education are the greatest early in the disease process. Most patients (73\%) attended MS 101 within the first three months since diagnosis, which aligned with Forbes's recommendations. However, the MS 101 course is only offered quarterly, which can limit the timeframe in which patients can attend.

Box et. al (2003) evaluated the prevalence of patient education occurring within the first year since diagnosis of MS, and reported an increase from $14 \%$ in 1974 to $72 \%$ in 2000. This study aligned with the work of Box et. al. with $100 \%$ of the participants obtaining formal education related to their condition within one year of a formal diagnosis. In addition, the MS 101 course covered information about MS symptoms, medication options, disease course and allowed for interaction with an MS certified nurse. These were the most commonly reported areas of patient education need as by Box (2003). However, in contrast to the work by Box, the MS 101 program had a considerable amount of information regarding symptom management, which Box (2003) had reported as being the biggest gap in patient education.

One of the major goals of this research was to establish the optimal timeframe in which formal patient education should be completed for individuals newly diagnosed with MS to optimize their ability to self-advocate. This goal was supported by the work of Chiovetti (2006) who reported on the critical need for patient education to occur at an appropriate time and at the appropriate levels. However, we were unable to identify what the critical timeframe is for this patient population. In addition, without retention tests, 
we cannot speak to the amount of information that was provided in the MS 101

programming. Chiovetti (2006) also described the importance of health literacy and ensuring all patient education materials were written to a level that all patients could understand. Although there was no formal assessment of this, MS 101 course organizers reported that course materials were developed at a third grade reading level.

Chiovetti (2006) has documented that formal patient education should occur in a friendly environment. The MS 101 course took place in a large conference room with space available for snacks and breaks as needed. The room was setup to promote discussion and involvement of all participants. An additional recommendation made by Chiovetti was for materials to be provided in written and verbal forms, through the use of Powerpoint and printed handouts.

Broadbent et. al. (2006) found that women with MS had higher reported selfmanagement skills than men, a result was not found to be significant in this study. Broadbent et. al. (2006) and Wilski and Tasiemski (2015) each reported that individuals with higher education levels scored higher on self-management questionnaires. This study did not find a correlation between education levels and PSAS scores. (See Table 4$13)$.

\section{Key Findings}

A major hypothesis of this study was that time since diagnosis of MS and patient reported self-advocacy would be correlated. We hypothesized that there would be an ideal timeframe in which patient education should be provided to maximize selfadvocacy. The findings of this study did not support these hypotheses. However, there 
were some important trends that were noted that offer insight to the value of this educational program and highlight further needs for education and research in this area.

PSAS item number 2 explores the likelihood of a patient seeking out information on the diagnosis. The mean score increased from 1.64 pre-course to 1.72 post-course. Although this change was not statistically significant, it suggested that patients may be less likely to seek out additional information, which may indicate the MS 110 course made he feel they were adequately informed about their diagnosis at that time.

PSAS item number 3 decreased from 2.18 to 2.00 between pre and post-course surveys. This item assessed if patients felt they were more educated than the typical US citizen about their own health. A decrease of 0.18 was not statistically significant but suggested patients believed their education level had improved and provided additional support of the value of patient education.

One of the more meaningful changes reported here was PSAS item number 4 that decreased from 3.73 to 2.55 for an overall change of 1.18. This change suggested that patients understood their condition better following formal education. A better understanding of the condition following patient education might imply the importance of offering educational programs early in the disease process.

Item number 11 was also an importance factor in this study as it assessed how likely patients were to advocate for beliefs after receiving formal education. A decrease in PSAS scores from 3.64 to 3.45 was not statistically significant but again suggests that educational programs increased self-advocacy and empowered patients to act on their own behalf in regards to medical care. 
The last PSAS item that supported this hypothesis was number 12 which determined how likely patients were to not comply with physician recommendations. A decrease in mean scores from 3.73 to 3.27 was noted here which indicated that patients were more likely to be compliant. This suggested that education offered insight into the condition, treatment options and was likely to promote patient compliance.

An addition major hypothesis of this study was that patient educational attainment and reported self-advocacy would be correlated. Individual education level was compared with the change in PSAS scores; the Spearman rho correlation was .061 showing no correlation between patient formal education and PSAS scores.

Another hypothesis of this study was that the amount of education provided could impact self-advocacy scores. This data was not objectively collected in hopes of patients using feedback forms or discussion to offer insight in this area. However, patients did not provide any meaningful feedback as to the length of the program or content that offered strong recommendations into potential program modification.

This research suggests the importance of patient education and the need to ensure timely delivery of education to maximize self-advocacy. The trend in averages between pre and post-course PSAS scores suggests that patient education was successful in allowing patients to better understand their diagnosis and various treatment options related to their condition. Another important trend in scores was increased likeliness of seeking out information related to their condition, which suggests that patients had a better understanding on how to seek out information and about resources available to them. PSAS item number 8 showed that after the MS 101 course individuals were less likely to question physicians when they did not agree with a recommendation. This 
suggests that patients have improved trust in their healthcare team following education provided by members of the comprehensive MS team. PSAS item 10 showed a trend towards individuals feeling that they had better awareness of their needs following and MS 101 program. PSAS item number 11 showed a trend towards patients reporting that they were more likely to advocate for their healthcare needs following an educational program. All of these trends support the value of patient education and the need for patient education to be readily available to patients. This information is valuable to the funding sources that support programs such as MS 101 in continuing to provide this programming to maximize patient potential. An additional value of the MS 101 program is the experience itself where individuals are able to interact with others with their condition and develop a bond with healthcare providers to help them feel more supported.

\section{Limitations of the Study}

There were several limitations to this study, the most prominent of which was the small number of participants resulting in low power for statistical analysis. The total enrollment for the study was 11 participants. Every individual approached about the study agreed to participate, so none were excluded. One potential reason for low enrollment was the relatively short duration of data collection, which spanned over a nine month period but with only three offerings. In addition to the limited course offerings, the timing of the courses may not have been reasonable for patients who work as the general timeframe was $1 \mathrm{pm}-5 \mathrm{pm}$ on a weekday.

Another limitation of this study was it only evaluated the immediate impact of the educational program without long-term follow-up to assess the program effectiveness on 
patient self-advocacy or educational needs which would be essential to assess the cognitive load theory implications on retention of large amounts of information. In future studies, a baseline evaluation of individual's knowledge of MS prior to the MS 101 courses should be used and compared to post-test values to assess program material comprehension. Further research should also include an assessment of knowledge retention. According to the cognitive load theory, learners can become overwhelmed when trying to process and transfer large amounts of information from working memory to long term memory. An immediate post-test and a retention test would allow researchers to evaluate components of cognitive load theory specific to this patient population.

This study evaluated only one educational program at one comprehensive MS center, providing limited ability to apply to other such programs and threatening external validity. Other centers that use different strategies for patient education may not be able to generalize the findings of this study to standardize educational procedures.

Factors affecting internal validity were also present in this study. There was no baseline assessment done to evaluate prior knowledge of MS. Patient intake forms assessed prior MS education with no patients reporting previous understanding or knowledge. However, it is likely that some patients had sought to educate themselves about the diagnosis through other means. There is also the potential that some patients could have a medical background and/or have previous knowledge of MS through friends or relatives with the same diagnosis.

An additional threat to internal validity was the potential for psychological changes within the patient during the study. Although pre and post measures were 
collected on the same day, there may have been experiences during the course that could have affected patient-reported outcomes. For example, some patients may have been motivated or discouraged by hearing about other people's experiences, which could have impacted their self-advocacy scores.

The testing component could have some impact on study validity as well. The same measure (PSAS) was used as a pre-test and post-test, but the potential for fatigue exists. Patients may have become fatigued during the four-hour course or had external factors that caused them to answer quickly or put less effort into their responses in an effort to complete the study and leave sooner.

This study lacked randomization; a sample of convenience was used based on patients who had elected to attend the MS 101 courses that occurred during the data collection period. All patients were given the option to participate after consent was given and educated about the role of the researcher. There is a possibility that patients felt obligated to agree to participate since they were approached directly by the researcher, who was also identified as a member of the MS treatment team. Patients may have perceived this situation as pressure to participate, although during the consent process, they were assured that participation was voluntary and confidential.

A potential impact on applicability of this study is that only the MS 101 course at Norton Healthcare was evaluated, which limits the generalizability of the findings to only this educational program. The current model for patient education at Norton Healthcare for other progressive neurologic conditions such as Parkinson's disease is similar to MS 101. Other MS centers have varying methods of patient education - most centers provide education online, and some centers provide shared medical appointments where patients 
interact in small groups with a provider to be educated on their diagnosis. There is limited research supporting the efficacy of these types of educational programs.

\section{Recommendations for future research}

As a result of this research study, many suggestions for future research can be made. This research did not specifically look at the length of the MS 101 course and the potential implications of the cognitive load theory. Previous researchers hypothesized that an educational program that is too long or that provides too much information may affect the learner's ability to comprehend or retain the material. Some means of evaluating and making recommendations for the ideal length of educational programs would be useful in planning future programming and optimizing the information provided to patients. Cognitive load theory refers to an individual's ability to absorb new information and recognize individual differences, but a large study could make some general recommendations in regards to program length. Ideally, a comparative study that collects feedback from two MS 101 programs, one of shorter length and one more comprehensive and then evaluates comprehension, retention and patient feedback on the volume of information would be helpful. That data should be compared with post-course comprehension and retention scores to objectively document differences.

Future studies in this area should also consider a baseline cognitive assessment, specifically when interested in the cognitive load theory or retention of education.

Depending on the size and location of MS lesions, memory and cognitive function could be impaired even within the first year of diagnosis, which would impact an individual's ability to comprehend and retain information provided in MS 101 courses and could further impact their PSAS scores. Additionally, patients that have difficulty 
understanding or retaining information may become frustrated with the program and this could impact PSAS scoring. One method to assess this would be to provide a baseline cognitive assessment and evaluate for any correlation between scores on these assessments and self-reported PSAS scores.

Additionally, supplementary subjective feedback from patients on the content, length and presenters of the program should be gathered. A general course review was provided but patient comments were not a part of that review.

This study assessed only one center's approach to educating patients that are newly diagnosed with MS. In future studies, a comparative analysis that studies at different models would be helpful. This could lead to standardized formal education programs and provide a framework for newer MS programs on optimal formatting for patient education.

A significant portion of the MS 101 course addressed the impact of MS on the lpatients' lives, disclosure of the diagnosis to family and friends, and future barriers, including coping skills, anxiety, depression, missed work and disability. However, there was no objective measure such as a quality of life tool taken during this study to assess how MS had impacted the lives of the patients that participated. In future research, this would be a valuable tool to track the impact at the time of diagnosis and as the disease progresses.

One major goal of this study was to examine the MS 101 program and determine the relationship between time since diagnosis and perceived self-advocacy and recommend an ideal timeframe in which patient education should be initiated and 
completed. Future studies may consider motivation as a correlate between attendance and self-advocacy. Patients may have attended programs based on their own interest or goals or attended at the request of family members. Patient motivation and self-advocacy may indeed be related.

A significant component of the self-advocacy questionnaire involves patient interactions with physicians and willingness to ask questions and interact with providers. Future research should consider previous interactions with physicians as a possible factor in self-advocacy. Patients may have seen multiple providers through the diagnostic process or had other encounters with healthcare professionals that played a critical role in self-reported PSAS scores. For example, a negative interaction with a past provider may influence patients' ability to advocate for needs and this factor should be considered in further research.

An additional factor that should be considered is the level of family support. Many patients attending MS 101 were accompanied by spouses, parents or other family members, but this data was not formally collected. In future studies, this may be a critical factor to consider. Some individuals may rely heavily on family members during medical appointments, which could impact their reported self-advocacy measures. In other cases, family may be less involved and place more demands on the individual to manage their own medical needs. This factor may become especially important in individuals with cognitive impairments.

In this research, no specific information was collected about each individual's disease, such as the type of MS (if known), number of lesions, relapses, responses to medications or aggressiveness of their disease. One standardized tool for assessing the 
level of impairment in MS is the Expanded Disability Status Scale (EDSS) which evaluates the level of function specific to mobility. Obtaining this information would require access to medical records and physician documentation, but may offer an interesting area of research to determine if there are correlations between the level of disability and patient-reports self-advocacy.

Finally, another area for future research is long-term follow-up to determine is self-advocacy at diagnosis translated into improved outcomes or improved disease management. For this research to be completed there would need to be a lengthy study following patients over several years, which could present challenges with research personnel and the ability to monitor patients for prolonged periods of time.

\section{Researcher Observations}

There were several observations made by the researchers during this study that warrant discussion. Although MS 101 is presented by a nurse and social worker, which supports the multidisciplinary approach, there would likely be great value in a brief discussion with a patient who has lived with MS for some time. This would allow newly diagnosed individuals to learn from the experience of others they may relate better to. This would also allow for individuals to possibly ask questions from someone they view as a peer that they may not necessarily bring up with medical professionals.

Additionally, this opportunity would likely generate some personal relationships that could be beneficial to individuals as they cope with their diagnosis.

In recommendations to Norton Healthcare, it was suggested that the MS 101 course be decreased to three hours with challenging topics such as coping and disability being removed. Through observation, I found that these difficult discussions changed the 
energy of the course, resulted in some individuals withdrawing from discussion and becoming more emotional. Since this suggestion was made, the program has been modified and the abbreviated MS 101 course begins in February 2017. Additionally, I suggested an optional MS 102 course that could run once or twice per year specifically to address issues with disclosure, employment or disability. I also suggested that providers strive to limit their referrals to MS 101 programs to those individuals diagnosed within one-year timeframes. In one observation, I noted a patient with a more aggressive form of MS who had been diagnosed for several years attending the program and noted some changes in discussion that could be viewed as intimidating to newly diagnosed individuals. 


\section{REFERENCES}

Aalto, A., Uutela, A., Aro, A. (1997). Health related quality of life among insulindependent diabetics: disease-related and psychosocial correlates. Patient Education Council,30:215-225.

Baldwin, M. (2003). Patient advocacy: A concept analysis. Nursing Standard, 17, 3339.

Bandura, A. (1977). Self-efficacy: toward a unifying theory of behavioral change. Psychology Review, 84, 191.

Benito-Leon, J., Manuel Morales, J., Rivera-Navarro, J., Mitchell, A. (2003). A review about the impact of multiple sclerosis on health-related quality of life. Disability Rehabilitation, 25:1291-1303.

Bishop, M., Frain, M., Espinosa, C., Stenhoff, D. (2009). Sources of information about multiple sclerosis: Information seeking and personal, demographic, and MS variables. Journal of Vocational Rehabilitation,31: 107-117.

Bjornevik, K., Riise, T., Cortese, M., Holmoy, T., Kampman, M., Magalhaes, S., Wolfson, C. \& Pugliatti, M. (2015). Level of education and multiple sclerosis risk after adjustment for known risk factors: The EnvIMS study. Multiple Sclerosis.

Bombardier, C., Wadhwani, R., \& LaRotonda, C. (2005) Health promotion in people with multiple sclerosis. Physical Medicine and Rehabilitation Clinics of North America, 16: 557-570.

Box, V., Hepwroth, M., \& Harrison, J. (2003). Identifying information needs of people with multiple sclerosis. Clinical Research \& Development,99:32-36.

Brashers, D., Haas, S., \& Neidig, J. (1999). The patient self-advocacy scale: Measuring patient involvement in health care decision-making interactions. Health Communications, 11(2), 97-121.

Brashers, D., Klingle, R. (1992). The influence of activism on physician-patient communication. Paper presented at the annual meeting of the Speech Communication Association, Chicago, IL.

Briggs, F., Acuna, B., Shen, L., Bellesis, K., Ramsay, P., Quach, H., Bernstein, A., Schaefer, C., \& Barcellos, L., (2014). Adverse socioeconomic position during the life course is associated with multiple sclerosis. Journal of Epidemiology \& Community Health, 68: 622-629. 
Brissart, H., Morele, E., Baumann, C., Perf, M., Leininger, M., Taillemite, L., Dillier, C., Pittion, S., Spitz, E., Debouverie, M. (2013). Cognitive impairment among different clinical courses of multiple sclerosis. Neurologic Research, 35(8):86772 .

Broadbent, E., Petrie, K., Main, J., Weinman, J. (2005). The Brief Illness Perception Questionnaire. Journal of Psychosomatic Research, 60(6):631-637.

Burks, J., \& Johnson, K. (2000). Multiple sclerosis: Diagnosis, medical management and rehabilitation. New York, NY: Demos Medical.

Bury, T. J., \& Stokes, E. K. (2012). A global view of direct access and patient selfreferral to physical therapy: Implications for the profession. Physical Therapy, 93, 449-459.

Caine, E., Schwid, R. (2002) Multiple sclerosis, depression, and the risk of suicides. Neurology, 59:674-8.

Caldwell, J. (2011). Disability identity of leaders in the self-advocacy movement. Intellectual and developmental disabilities, 49(5), 315-326.

Chiovetti, A. (2006). Bridging the gap between health literacy and patient education for people with multiple sclerosis. Journal of Neuroscience Nursing;38: 374-378.

Chwastiak, L., Ehde, D., Gibbons, L., Sullivan, M., Bowen, J., \& Kraft, G. (2002). Depressive symptoms and severity of illness in multiple sclerosis: epidemiologic study of a large community sample. American Journal of Psychiatry, 159:18621868.

Covey, S. The 7 habits of highly effective people: Powerful lessons in personal change. New York: Fireside, 1990.

Dahnke, G., Garlick, R., \& Kazoleas, D. (1994). Testing a disease-specific health locus of control scale among cancer and aplastic anemia patients. Health Communication, 6, 37-53.

Emrich, I. A., Frohlich-Guzelsoy, L., Bruns, F., Friedrich, B., \& Frewer, A. (2014). Clinical ethics and patient advocacy. HEC Forum, 26:111-124.

Ende, J., Kazis, L., Ash, A., \& Moskowitz, M. (1989). Measuring patients' desire for autonomy: Decision making and information-seeking preferences among medical patients. Journal of General Internal Medicine, 4, 23-30.

Feicke, J., Sporhase, U., Kohler, J., Busch, C., Wirtz, M. A multicenter, prospective, quasi-experimental evaluation study of a patient education program to foster 
multipler sclerosis self-management competencies. (2014). Patient Education and Counseling, 97:361-369.

Folkman, S., \& Lazarus, R. (1980). An analysis of coping in a middle-aged community sample. Journal of Health and Social Behavior, 21, 219-239.

Ghajarzadeh, M., Owji, M., Sauraian, M., Naser Moghadasi, A., Azimi, A. (2014). Emotional intelligence (EI) of patients with multiple sclerosis. Iran Journal of Public Health, 42(11)1550-6.

Ghajarzadeh, M., Jalilian, R, Eskandari, G., Sahraian, M.A., Azimi, A., Mohammadifar, M. (2013). Fatigue in multiple sclerosis: relationship with disease duration, physical disability, disease pattern, age, and sex. Acta Neurologica Belgica, 113(4):411-4.

Ghajarzadeh, M., Jalilian, R., Eskandari, G., Ali Sahraian, N., Reza Azimi, A., (2013). Validity and reliability of Persian version of Modified Fatigue Impact Scale (MFIS) questionnaire in Iranian patients with multiple sclerosis. Disability \& Rehabilitation, 35(18):1509-12.

Halper, J. (2010). The evolution of nursing care in multiple sclerosis. The International Journal of MS Care, 2(1), 14-22.

Halper, J., \& Holland, N. J. (1996). Comprehensive nursing care in multiple sclerosis. New York, NY: Demos Vermande.

Heesen, C., Kopke, S., Richter, T., \& Kasper, J. (2007). Shared decision making and self-management in multiple sclerosis - a consequence of evidence. Neurology, 254: $116 / 121$.

Heesen, C., Kasper, J., Segal, J., Kopke, S. \& Muhlhauser, I. (2004). Decisional role preferences, risk knowledge and information interests in patients with multiple sclerosis.

Hermansen-Kobulnicky, C. J. (2008). Measurement of self-advocacy in cancer patients and survivors. Support Care Center, 16:613-618.

Hughes, A., Beier, M., Hartoonian, N., Tuener, A., Amtmann, D., Ehde, D. (2015). Selfefficacy as a longitudinal predictor of perceived cognitive impairment in individuals with multiple sclerosis. Archives of Physical Medicine and Rehabilitation, 96:913-919.

Huijbregts, S., Kalkers, N., doSonneville, L., de Groot, V., Reuling, I., Polan, C. (2004). Differences in cognitive impairment of relapsing remitting, secondary, and primary progressive MS. Neurology,27;63(2):335-9. 
Hyland, D. (2002). An exploration of the relationship between patient autonomy and patient advocacy: Implications for nursing practice. Nursing Ethics, 9(5), 472482.

Janardhan, V., Bakshi, R. (2002). Quality of life in patients with multiple sclerosis: the impact of fatigue and depression. Journal of Neurological Science, 205: 51-58.

Johnson, J. (2003). On receiving the diagnosis of multiple sclerosis: Managing the transition, Multiple Sclerosis, 9:82-88.

Jonikas, J. A., Grey, D. D., Copeland, M. E., Razzano, L. A., Hamilton, M. M., Floyd, C. B., Hudson, W. B., \& Cook, J. A. (2013). Improving propensity for patient selfadvocacy through wellness recovery action planning: Results of a randomized controlled trial. Community Mental Health Journal, 49,260-269.

Kalyuga, S. (2015). Instructional guidance: A cognitive load perspective. Charlotte: Information Age Publishing, Inc.

Kieseier, B. (2015). Multiple sclerosis - a dynamic field with a need for excellent education. European Journal of Neurology, 22:1-2.

Kern, S., Schrempf, W., Schneider, H., Schultheiss, T., Reichmann, H., Ziemssen, T. (2009). Neurological disability, psychological distress, and health-related quality of life in MS patients within the first three years after diagnosis. Multiple Sclerosis, 15(6):752-8.

Kopke, S., Kasper, J., Muhlhauser, I., Nubling, M., Heesen, C. (2009). Patient education program to enhance decisions autonomy in multiple sclerosis relapse management: a randomized-controlled trial. Multiple Sclerosis, 15,96-104.

Kopke, S., Solari, A., Khan, F., Heesen, C., \& Giordano, A. (2014). Information provision for people with multiple sclerosis (Review). The Cochrane Collaboration.

Korostil, M., Feistein, A. (2007). Anxiety disorders and their clinical correlates in multiple sclerosis patients. Multiple Sclerosis, 13:67-72.

Krantz, D., Baum, A., \& Wideman, M. (1980). Assessment of preferences for selftreatment and information in health care. Journal of Personality and Social Psychology, 39, 977-990.

Kroencke, D., Lynch, S., Denney, D. (2000). Fatigue in multiple sclerosis: relationship to depression, disability, and disease pattern. Multiple Sclerosis, 6:131-136.

Kurtzke, J. (1961). On the evaluation of disability in multiple sclerosis. Neurology, 11:686. 
Kurtzke, J. (1983). Rating neurological impairment in multiple sclerosis: An expanded disability status scale (EDSS). Neurology,33:1444.

Lackner, J., Carosella, A., Feuerstein, M. (1996). Pain expectancies, pain, and functional self-efficacy expectancies as determinants of diability in patients with chronic low back disorders. Journal of Consultative Clinical Psycholog,64:212.

Loffler, L., Radke, S., Morawetz, C. Derntl, B. (2015). Emotional dysfunctions in neurodegenerative diseases. Journal of Comparative Neurology. Accessed at http://www.ncbi.nlm.nih.gov/pubmed/26011035 ahead of print.

Lynch, S., Kroencke, D., Denney, D. (2001). The relationship between disability and depression in multiple sclerosis: the role of uncertainty, coping, and hope. Multiple Sclerosis, 7(6):411-6.

Marks, R., Allegranta, J. (2005). A review and synthesis of research evidence for selfefficacy-enhancing interventions for reducing chronic disability: implications for health education practice (part II). Health Promotion Practice,6:148-156.

Martins Da Silva, A., Cavaco, S., Moreira, I. Bettencourt, A. Santos, E. Pinto, C. Goncalves, A., Coutinho, E., Samoes, R., Dias, C., Teizeira-Pinto, A., Montalban, $\mathrm{X}$. Cognitive reserve in multiple sclerosis: Protective effects of education. Multiple Sclerosis, 21(10), 1312-1321.

Matti, A., McCarl, H., Klaer, P., Keanne, M. \& Chen, C. (2010). Multiple sclerosis: patients' information sources and needs on disease symptoms and management. Patient Preference and Adherence, 4:157-161.

Middleton, L., Denney, D., Lynch, S., \& Parmenter, B. (2006). The relationship between perceived and objective cognitive functioning in multiple sclerosis. Archives of Clinical Neuropsychology, 21:487-494.

Mitchell, G., \& Bournes, D. (2000). Nurse as patient advocate? In search of straight thinking. Nursing Science Quarterly, 13(3), 204-209.

Moccia, M., Carotenuto, A., Massarelli, M., Lanzillo, R., \& Brescia Morra, V. (2015). Can people with multiple sclerosis actually understand what they read in the Internet age? Journal of Clinical Neuroscience. Epub ahead of print.

Moccia, M., Lanzillo, R., Palladino, R., Chang K. C., Costabile, T., Russo, C., DeRosa, A., Carotenuto, A., Sacca, F., Maniscalco, G. T., \& Brescia Morra, V. (2015). Cognitive impairment at diagnosis predicts 10-year multiple sclerosis progression. Multiple Sclerosis. 
Mohr, D., Goodkin, D., Gatto, N,. Van der Wende, J. (1997). Depression, coping and level of neurological impairment in multiple sclerosis. Multiple Sclerosis, 3(4):254-8.

Mohr, D., Hart, S., Fonareva, I., Tasch, E. (2006). Treatment of depression for patients with multiple sclerosis in neurology clinics. Multiple Sclerosis, 12:204-208.

Moore, P., Harding, K., Clarkson, H., Pickersgill, T., Wardle, M., \& Robertson, N. (2013). Demographic and clinical factors associated with changes in employment in multiple sclerosis. Multiple Sclerosis, 19, 1647-1654.

Mulley, A., Trimble, C., and Elwyn, G. (2012). Stop the silent misdiagnosis: patients' preferences matter. British Medical Journal, 345: 1-6.

Namey, M., Costello, K., Halper, J., \& Harris, C. (2010). “Advocacy in multiple sclerosis." (White Paper). Consortium of Multiple Sclerosis Centers.

National Mental Health Consumer's Self-Help Clearinghouse. Advocacy and recovery using the internet. Philadelphia: National Mental Health Consumers' Self-Help Clearinghouse, undated. Accessed at www.myselfhelp.org.

National Mental Health Consumer's Self-Help Clearinghouse. Technical assistance guide: Self-advocacy. Philadelphia: National Mental Health Consumers' SelfHelp Clearinghouse, undated. Accessed at www.myselfhelp.org.

Neri, M., \& Kroll, T. (2003). Understanding the consequences of access barriers to health care: experiences of adults with disabilities. Disability and Rehabilitation, 25(2), 85-96.

Nielsen, N., Jorgensen, K., Bager, P., Stenager, E., Pedersen, B., Koch-Henriksen, N., \& Frisch, M. (2013). Socioeconomic factors in childhood and the risk of multiple sclerosis. American Journal of Epidemiology, 177: 1289-1295.

Northern, K. (2001). Effects of a self-management program on patients with chronic disease. Effective Clinical Practice,4:256-262.

Noseworthy, J., Vandervoort, M., Wong, C. \& Ebers, G. (1990). Interrater variability with the Expanded Disability Status Scale (EDSS) and Functional Systems (FS) in a multiple sclerosis clinical trial. The Canadian Cooperation MS Study Group. Neurology,40: 971-975.

O’Day, B., \& Goldstein, M. (2005). Advocacy issues and strategies for the $21^{\text {st }}$ century. Journal of Disability Policy Studies. 15(4). 240-250. 
Paas, F., \& Sweller, J. (2012). An evolutionary upgrade of cognitive load theory: Using the human motor system and collaboration to support the learning of complex cognitive tasks. Educational Psychology Review, 24:27-45.

Paas, F., van Gog, T., \& Sweller, J. (2010). Cognitive load theory: New conceptualizations, specifications, and integrated research perspectives. Educational Psychology Review, 22,115-121.

Pahlavanzadeh, S., Dalvi-Isfahani, F., Alimohammadi, N., Chitsaz, A. The effect of group psycho-education program on the burden of family caregivers with multiple sclerosis patetsn in Isfahan in 2013-2014. Iranian Journal of Nursing and Midwifery Research. 20(12): 420-425.

Paty, D., Noseworthy, J., \& Ebers, G. Diagnosis of multiple sclerosis. In Multiple Sclerosis. Philadelphia, PA: FA Davis; 1998, 48-50.

Pickett, S., Diehl, S., Steigman, P. J., Prater, J. D., Fox, A., Shipley, P., Grey, D. D., \& Cook, J. A. (2012). Consumer empowerment and self-advocacy outcomes in a randomized study of peer-led education. Community Mental Health, 48,420-430.

Polman, C., Thompson, A., Murray, T., Bowling, A., \& Noseworthy, J. (2006). Multiple sclerosis: The guide to treatment and management. New York, NY: Demos Medical.

Reed, T. (1989). Do union organizers matter? Individual differences, campaign practices, and representation election outcomes. Industrial and Labor Relations Review, 43, 103-119.

Rogers, E., Ralph, R., Saizer, M. (2010). Validating the empowerment scale with a multisite sample of consumers of mental health services. Psychiatric Services, 61(9):933-936.

Rumrill, P., \& Roessler, R. (2015). An overview of multiple sclerosis: Medical, psychosocial, and vocational aspects of a chronic and unpredictable neurological disorder. Rehabilitation Research, Policy, and Education,29(2), 122-134.

Sadovnick, A., Remick, R., Allen, J., Swartz, I., Yee, I., Eisen, K., Farquhar, R., Hashimotor, S., Hooge, J., Kastrukoff, L., Morrison, W., Nelson, J., Oger, J., \& Patty, D. (1996). Depression and multiple sclerosis. Neurology, 46, 628-632.

Schwartz, L. (2002). Is there an advocate in the house? The role of health care professionals in patient advocacy. Journal of Medical Ethics, 28, 37-40.

"Self Advocacy". Retrieved from the National Coalition for Cancer Survivorship. Accessed at www.canceradvocacy.org. 
Shevell, M. (2008). The neurological advocate? The Canadian Journal of Neurological Sciences, 35(5), 542-543.

Smith, R., Wallston, B., Wallston, K., Forsberg, P., \& King, J. (1984). Measuring desire for control in health care processes. Journal of Personality and Social Psychology, 47, 415-426.

Somerset, M., Campbell, R., Sharp, D., \& Peters, T. (2001). What do people with MS want and expect from health-care services? Health Expectations, 4:29-37.

Sweller, J. (2009). The many faces of cognitive load theory. $T+D, 63: 8$.

Swinkels, I. C. S., Kooijman, M. K., Spreeuwenberg, P. M., Bossen, D., Leemrijse, C. J., van Dijk, C. E., Verheij, R., de Bakker, D. H., \& Veenhof, C. (2014). An overview of 5 years of patient self-referral for physical therapy in the Netherlands. Physical Therapy,94:1785-1795.

Synnot, A., Garner, K., Summers, M., Fillippini, G., Osborne, R., Shapland, S., Colombo, C., \& Mosconi, P. (2014). Online health information seeking: how people with multiple sclerosis find, assess and integrate treatment information to manage their health. Health Expectations. Epub ahead of print.

The National Collaborating Centre for Chronic Conditions. Multiple Sclerosis. National clinical guideline for diagnosis and management in primary and secondary care. The National Collaborating Centre for Chronic Conditions. (2004). http://www.nice.org.uk/nicemedia/live/10930/46699/46699.pdf

Till, C., Udler, E., Ghassemi, R., Narayann, S., Arnolds, D., Banwell, B. (2012). Factors associated with emotional and behavioral outcomes in adolescents with multiple sclerosis. Multiple Sclerosis, 18(8):1170-80.

Tsaousides, T., Warshowsky, A, Ashman, T., Cantor, J., Spielman, L., Gordon, W. (2009). The relationship between employment-related self-efficacy and quality of life following traumatic brain injury. Rehabilitation Psychology;54:299.

Vahdat, S., Hamzehgardeshi, L., Hamzehgardeshi, Z., \& Hessam, S. Psychometric properties of the patient self-advocacy scale: The Persian version. IJMS, 40(4)349-355.

Vickrey, B., Shatin, D., Wolf, S. (2000). Management of multiple sclerosis across managed care and fee-for-service systems. Neurology,55:1341-1349.

Walsh-Burke, K. \& Marcusen, C. (1999), Self-advocacy training for cancer survivors. Cancer Practice, 7: 297-301.

"What is self advocacy?" Retrieved from www.nationalMSSociety.org. 
Wilski, M., \& Tasiemski, M. (2015). Illness perception, treatment beliefs, self-esteem, and self-efficacy as correlates of self-management in multiple sclerosis. Acta Neurologia Scandinavica. Accepted for publication, June 25, 2015.

Wineman, N., Durand, E., \& Steiner,R. (1994). A comparative analysis of coping behaviors in persons with multiple sclerosis or a spinal cord injury. Research in Nursing \& Health, 17:185-194. 